\title{
Innovation and the Emergence of Market Dominance
}

\author{
Susan Athey and Armin Schmutzler \\ This Draft: October, 1999.
}

ABstraCt: This paper analyzes a model of oligopolistic competition with ongoing investment. It incorporates the following models as special cases: incremental investment, patent races, learning-by-doing, and network externalities. We investigate circumstances under which a firm with low costs or high quality will extend its initial lead through further cost-reducing or quality-improving investments. In many commonlystudied oligopoly games, such investments are strategic substitutes. We derive a new comparative statics result that applies to games with strategic substitutes, and we use the result to derive conditions under which leading firms invest more than lagging firms. We show that the conditions are satisfied in a variety of commonly-studied oligopoly models. We also highlight plausible countervailing effects from two distinct sources. First, leading firms may find it more costly than others to achieve the same increment to their state. This force is particularly salient in many models of patent races, where firms make research investments in an attempt to find a new technology that delivers a given level of cost or quality. Second, countervailing effects may arise in dynamic games with more than two firms, when firms are sufficiently patient.

JEL Classification Numbers: L11, L13, L41, O30.

Keywords: Oligopoly games, strategic substitutes, innovation, investment, increasing dominance, market concentration.

*Affiliations: Susan Athey, Department of Economics, Massachusetts Institute of Technology, 50 Memorial Drive, E52-252C, Cambridge, MA 02142, USA; and National Bureau of Economic Research. e-mail: athey@mit.edu. Armin Schmutzler, Sozialökonomisches Seminar, Universität Zürich, Blümlisalpstr. 10, 8006 Zürich, Switzerland, e-mail: arminsch@sozoec.unizh.ch.

We are grateful to Rabah Amir, Zava Aydemir, Kyle Bagwell, Abhijit Banerjee, Men-Andri Benz, Luis Cabral, Thomas Gehrig, Bob Gibbons, Aija Leiponen, Paul Milgrom, Wally Mullin, Andreas Polk, Mike Riordan, and seminar audiences at MIT, Freiburg, Torino (EARIE) and Zürich for helpful discussions. Thomas Borek provided excellent research assistance. Athey thanks the NSF (SBR-9631760) for financial support. 


\section{Introduction}

This paper studies the dynamics of market structure in a setting where firms have the opportunity to innovate, for example by investing in cost reduction. Our goal is to understand conditions under which firms with an initial advantage increase or decrease their investments and market shares over time. We focus on changes in concentration that arise through firms' choices about activities such as investment in research and development and advertising. We examine conditions under which weak increasing dominance emerges, whereby leading firms invest more into improving their state. We also discuss under which conditions this implies strong increasing dominance, whereby the higher investment levels of leading firms result in increasing market shares.

The empirical evidence about the dynamics of concentration illustrates that a variety of phenomena are possible. Increasing dominance of the market leader is not uncommon. The most obvious examples concern network effects or learning-by-doing. ${ }^{1}$ Increasing dominance has also been documented as arising through a process of cost-reducing or demand-enhancing investments in retail markets (Bagwell et al (1997)) and advertising-intensive industries (Sutton (1991), Bagwell and Ramey (1994)). ${ }^{2}$ On the other hand, increasing dominance does not always arise in such settings. ${ }^{3}$

To provide insight into these patterns, and we develop a general theoretical model of competition among two or more oligopolists. In our model, firms may make investments in each period, where we use the term "investment" very broadly. For example, firms may make investments in process innovations that lead to cost reduction, so that the current

\footnotetext{
${ }^{1}$ Network effects have been widely cited as the reason why VHS managed to rapidly extend comparatively negligible initial advantages over Betamax in the market for videocassette recorders; more recently, policymakers have focused on the role of network effects in computer operating systems and applications. Seminal models of network effects include Katz and Shapiro (1986) and Farrell and Saloner (1986). Learning-bydoing effects have been analyzed in the context of aircraft production and other manufacturing processes; see Cabral and Riordan (1994) for further examples.

${ }^{2}$ In another example, the empirical literature concerning the product cycle emphasizes that when a relatively mature stage of market development is reached, a shake-out of firms arises. Such a shake-out often arises because some firms manage to reduce production costs faster than others (Klepper 1996).

${ }^{3}$ Gruber's (1994) account of the semiconductor industry shows that the dynamic patterns within generations of memory chips vary from period to period and from product to product. IBM lost its early lead in the mainframe computer market to market entrants in the 1960's and 1970's (see Sutton 1998, ch.15), in spite of strong network effects. The aircraft industry is another example for a technology-intensive industry characterized by technological leapfropping between a small number of firms, resulting in leadership reversals and significant shifts in market shares.
} 
state of the firm depends on past investments. Investments can result in small incremental improvements relative to the earlier state, or else in major breakthroughs (as in stochastic R\&D-investment races). In a learning-by-doing or network externality setting, "investment" refers to a choice of output that exceeds the level that maximizes profits in a single period.

Our first result establishes a general set of conditions under which weak increasing dominance emerges when firms are myopic. We show that firms with higher state variables will invest more when the following conditions are met: (i) investments are strategic substitutes, (ii) product market payoffs are convex in the state variable, and (iii) adjustment costs do not rise too quickly with the level of the state variable. It should be noted that the result that (i)-(iii) imply weak increasing dominance is not immediate. In contrast to games with strategic complementarities (Topkis (1979), Vives (1990), and Milgrom and Roberts (1990)), where all choices are mutually reinforcing and thus comparative statics on equilibria can be easily obtained, multi-player games with strategic substitutes potentially have competing effects. $^{4}$ Indeed, much of the existing literature restricts attention to two-player games for just this reason. ${ }^{5}$ In this paper, we impose an alternative assumption: the firms' profit functions must be "exchangeable." That is, they must satisfy a certain kind of symmetry: all differences among firms are summarized by the state variables. Our result represents an extension of the comparative statics literature, and it may also be applied to other games with strategic substitutes. For example, we show that it can be used to consider questions about strategic trade policy.

Within the class of investment games, we show that forces arising naturally in many oligopoly models work in favor of conditions (i)-(ii). Consider the example of cost reduction, and consider decomposing a firm's product market profits into the product of a firm's markup and its equilibrium demand. Clearly, the higher is a firm's demand, the higher are the returns to lowering cost. In many models, an opponent's investment decreases a firm's equilibrium demand, and a firm's own investment increases its equilibrium demand. Thus, it is perhaps

\footnotetext{
${ }^{4}$ Observe that an increase in player 1's action has direct negative effects on all opponents; but the resulting decrease in player 2's action might lead to an even larger increase in player 3's action. Thus, the effect of an increase in player 1's state variable has ambiguous effects on player 3.

${ }^{5}$ This is the approach taken by Novshek (1985) in an analysis of Cournot oligopoly. Amir (1996) and Davis (1999) use the tools of games with strategic complementarities to analyze Cournot oligopoly games with more than two firms, but maintain the assumption that each firm cares only about the sum of opponent output.
} 
not surprising that a wide variety of commonly-used models satisfy conditions (i) and (ii), including: Bertrand and Cournot competition with differentiated goods and linear demand; horizontal competition on the line or on the circle with quadratic transportation costs; and some vertical quality differentiation models. We also show that our results can be extended to some cases where firms undertake more than one type of investment at the same time, such as quality-improving and cost-reducing investments. ${ }^{6}$

However, we have already noted that even in innovative industries, market dynamics do not always follow patterns of increasing dominance. What serves to mitigate the forces in favor of dominance? We only briefly discuss the potential for competing effects that arise due to product market competition, instead focusing on the properties of the technology with which state variables can be adjusted upwards (effect (iii)). Two polar examples serve to highlight the scenarios under which adjustment costs do or do not compete with increasing dominance effects. First, consider a stylized incremental investment model, where the cost of achieving a given increment to the state variable is the same for all firms, and independent of the state variables. Contrast this with a second example, where innovation takes place in a manner that is closer to what has been modeled in the literature on patent races: ${ }^{7}$ firms compete for the next technological innovation, and each firm requires a similar investment to achieve a given level of the state variable (or a given probability of achieving that level of the state variable) in the next period. In such models, the magnitude of improvement per unit of investment is larger for laggards than for leaders, and so leaders may invest less than laggards. However, the latter effect must be large to overcome forces (i) and (ii) from above. $^{8}$

In a second set of results, we relax the assumption that firms are myopic, and consider how concern for the future affects our results about dominance. We find that when the evolution of the state variable is deterministic and firms commit to an investment plan in advance, dynamics reinforce the results from the myopic-firm model. ${ }^{9}$ However, when we allow firms to

\footnotetext{
${ }^{6}$ Cabral (1999) proposes an alternative theory of increasing dominance that does not rely on the scale effects described above. He identifies a different force: leaders have an incentive to undertake R\&D investment with returns that are correlated with the laggards, while laggards desire an opportunity to leapfrog, which can be accomplished using independent investments.

${ }^{7}$ See Reinganum 1985, Vickers 1986, Beath et al. 1987, as well as the earlier patent race papers by Loury (1979) and Lee and Wilde (1980).

${ }^{8}$ Indeed, the literature highlights the fact that the results are sensitive to the specification of the model.

${ }^{9}$ This highlights an advantage to our lattice-theoretic approach: the theorem applies without modification
} 
condition each period's investment on the current level of the state variable, then a variety of competing effects can arise. Thus, we show that our results about increasing dominance are most robust in scenarios where firms are fairly short-sighted, or where investment strategies require advance planning and are difficult to modify once in place. ${ }^{10}$

Finally, we show that our framework can be used to organize and extend the results of specific models from the existing literature, including incremental investment games, learning-by-doing models, and patent races. ${ }^{11}$ Thus, our model provides a lens through which to analyze the extent to which increasing dominance should be expected in a particular industry.

We proceed as follows. In Section 2, we introduce the model. Section 3 contains the main results for this model. In Section 4, we present examples of the general framework and applications of the results from Section 3. Section 5 examines policy implications and conclusions.

\section{The Model}

This section specifies a model of dynamic oligopoly that is general enough to incorporate incremental investment races, patent races, learning-by-doing and network models as special cases. Our interpretations will vary across models; Section 4 makes the interpretations more precise in the context of the specific applications.

when the choice set for each player is an infinite series rather than a real number.

${ }^{10}$ In its focus on understanding general properties in a dynamic context, our paper is similar to Budd et al. (1993) who also apply a relatively abstract framework to identify factors favoring and preventing increasing dominance. Their paper considers a continuous-time game between two firms who make investments in changing the state variable, and each firm's profits depends on the state variable. They link the slope of the profit functions to investments, but they do not attempt to give conditions on oligopoly models that lead to increasing dominance.

${ }^{11}$ Consider some examples from the existing literature. Flaherty's (1980) incremental investment model allows for cost-reducing investment between two rounds of Cournot competition with homogenous goods. Dominance emerges. A similar effect is present in the product life cycle model of Klepper (1996), although the scale effect is dominated by others in some stages of the life cycle. In Bagwell et al. (1997), customers learn retail prices slowly and, by using low prices today, firms signal that they have low costs and will also have low prices in the future. This is credible if low-cost firms expect high future demand, which is the scale effect described earlier. Cabral and Riordan (1994) examine a duopoly model with random product sales, where a lucky firm that manages to sell a lot in early stages proceeds along its learning curve more rapidly, allowing it to set prices lower than the competitor, thereby increasing the chances of future sales and thus the chances of future learning. 
There are $T$ periods, $t=1, \ldots, T(T \leq \infty)$, and $I$ firms, $i=1, \ldots, I$. In each period $t$, firm $i$ is characterized by a state variable $Y_{i}^{t} \in \mathcal{Y}_{i}$, where $\mathcal{Y}_{i}$ is a partially ordered set, typically $\mathbb{R}$, though in a few applications we will have $\mathcal{Y}_{i}=\mathbb{R}^{n}$. Throughout the paper, we will order vectors using the standard, componentwise order: for $\mathbf{x}, \mathbf{x}^{\prime} \in \mathbb{R}^{n}, \mathbf{x} \geq \mathbf{x}^{\prime}$ if $x_{i} \geq x_{i}^{\prime}$ for $i=1, . ., n$. Since the goal of this paper is to analyze the dynamics of market share, we assume that $Y_{i}^{t} \geq Y_{j}^{t}$ implies that firm $i$ has greater market share than firm $j$. As such, the state variable might represent the extent of previous cost reductions from some initial level; a demand-enhancing parameter, such as product quality or a cumulated advertising level, or the number of product variants offered by a firm; or, a combination of demand and cost parameters.

Let $\mathbf{Y}^{t}=\left(Y_{1}^{t}, \ldots, Y_{I}^{t}\right) \in \mathcal{Y}=\times_{i} \mathcal{Y}_{i}$. The initial state of the market, $\mathbf{Y}^{0}=\left(Y_{1}^{0}, \ldots, Y_{I}^{0}\right)$, is exogenously given. Given $Y^{t-1}$, each firm chooses an action variable $a_{i}^{t} \in \mathcal{A}_{i}$, which influences the increment $y_{i}^{t}$ in the state variable. We will refer to this choice as an "investment." Let $\mathbf{a}^{t}=\left(a_{1}^{t}, \ldots, a_{I}^{t}\right) \in \mathcal{A}=\times_{i} \mathcal{A}_{i}$. The state vector of firm $i$ develops according to

$$
Y_{i}^{t}=Y_{i}^{t-1}+y_{i}^{t}
$$

In the simplest applications, $y_{i}^{t}=a_{i}^{t}$. However, to incorporate stochastic investment returns, we allow $\mathbf{y}^{t}=\left(y_{1}^{t}, \ldots, y_{I}^{t}\right)$ to be the realization of a random variable with distribution $H\left(\mathbf{y}^{t} \mid \mathbf{a}^{t}, \mathbf{Y}^{t-1}\right){ }^{12}$ In this case, investment may improve the distribution of the change in the state variable, as when $a_{i}^{t}$ represents an R\&D-effort.

Now consider representing the profits from product market competition. We wish to handle two distinct cases in a unified notation. In the first case, $\mathbf{a}^{t}$ is the vector of firm choices in product market competition. For example, it represents output choice in a learning-bydoing game. Then, we let $\pi^{i}\left(\mathbf{a}^{t}, \mathbf{y}^{t}, \mathbf{Y}^{t-1}\right)$ denote product market profit for firm $i$.

In the second case, investments precede product market competition. For example, $\mathbf{a}^{t}$ might represent the vector of cost-reducing investments. In this case, product market profits depend only on the state variables, and we do not formally model the product market competition. Instead, we let $\pi^{i}\left(\mathbf{a}^{t}, \mathbf{y}^{t}, \mathbf{Y}^{t-1}\right)$ represent the reduced-form profit to firm $i$ resulting from a product market equilibrium. Since in this case, investments affect product

\footnotetext{
${ }^{12}$ In many examples, such as incremental investment games, the distribution of $y_{i}^{t}$ in period $t$ depends only on $Y_{i}^{t-1}$ and $a_{i}^{t}$, not on the other firms' state variables and investments. In contrast, in patent race models, investments have externalities across firms.
} 
market competition only through the evolution of the state variable, for each $i$ there must exist a function $\hat{\pi}^{i}(\mathbf{Y})$ such that

$$
\pi^{i}\left(\mathbf{a}^{t}, \mathbf{y}^{t}, \mathbf{Y}^{t-1}\right)=\hat{\pi}^{i}\left(\mathbf{Y}^{t-1}+\mathbf{y}^{t}\right)
$$

We refer to the function $\pi^{i}$ when deriving general results about our model, and we analyze the case where (2) holds in greater depth in Section 3.3 and in the context of applications.

We write the expected product market profit to firm $i$ as follows:

$$
E \pi^{i}\left(\mathbf{a}^{t}, \mathbf{Y}^{t-1}\right) \equiv \int \pi^{i}\left(\mathbf{a}^{t}, \mathbf{y}^{t}, \mathbf{Y}^{t-1}\right) d H\left(\mathbf{y}^{t} \mid \mathbf{a}^{t}, \mathbf{Y}^{t-1}\right)
$$

We further allow for an investment cost function, denoted $k^{i}\left(a_{i}^{t}, Y_{i}^{t-1}\right)$ for firm $i$, which is assumed to satisfy:

$$
k^{i}\left(a_{i}^{t}, Y_{i}^{t-1}\right) \text { is non-decreasing in } a_{i}^{t}
$$

Thus, the expected payoff to firm $i$ in period $t$ is written

$$
\Pi^{i}\left(\mathbf{a}^{t}, \mathbf{Y}^{t-1}\right)=E \pi^{i}\left(\mathbf{a}^{t}, \mathbf{Y}^{t-1}\right)-k^{i}\left(a_{i}^{t}, Y_{i}^{t-1}\right)
$$

To keep the exposition concise, we assume that all of the relevant functions are differentiable, though our main results do not rely on that assumption. Throughout the paper, we will use subscripts to note partial derivatives of $\Pi^{i}$ and $E \pi^{i}$, as follows: $\Pi_{a_{i}}^{i}(\mathbf{a}, \mathbf{Y}) \equiv$ $\frac{\partial}{\partial a_{i}} \Pi^{i}(\mathbf{a}, \mathbf{Y}), \Pi_{a_{i}, Y_{i}}^{i}(\mathbf{a}, \mathbf{Y}) \equiv \frac{\partial^{2}}{\partial a_{i} \partial Y_{i}} \Pi^{i}(\mathbf{a}, \mathbf{Y}),\left(E \pi^{i}\right)_{a_{i}, Y_{i}}=\frac{\partial^{2}}{\partial a_{i} \partial Y_{i}} E \pi^{i}(\mathbf{a}, \mathbf{Y})$, and likewise for the other variables.

We will assume throughout the paper that an equilibrium exists. ${ }^{13}$ Further, we maintain the assumption that the equilibrium is "conditionally unique," that is, the following condition is satisfied: for each $i, j$ and each $\mathbf{Y}$, if $Y_{i} \neq Y_{j}$ and there exist two equilibria, $\mathbf{a}^{*}(\mathbf{Y}), \tilde{\mathbf{a}}^{*}(\mathbf{Y})$ such that $a_{-i j}^{*}(\mathbf{Y})=\tilde{a}_{-i j}^{*}(\mathbf{Y})$, then $a_{i}^{*}(\mathbf{Y})=\tilde{a}_{i}^{*}(\mathbf{Y})$ and $a_{j}^{*}(\mathbf{Y})=\tilde{a}_{j}^{*}(\mathbf{Y})$. In words, conditional on firms $k \neq i, j$ playing equilibrium actions $\mathbf{a}_{-i j}^{*}(Y)$, if firms $i$ and $j$ have different state variables, there is a unique equilibrium. For the case where $\pi^{i}$ represents a reduced-form

\footnotetext{
${ }^{13}$ This assumption might be restrictive in some cases. The literature on existence of equilibrium in Cournot quantity games might be instructive here (Novshek (1985), Amir (1996), Davis (1999)), as this work concerns games with strategic substitutes; but, each of these papers considers models where firms care only about the sum of opponent outputs.
} 
profit function from competition in the product market, we impose the conditional uniqueness assumption on the product market equilibrium as well.

The assumption of conditional uniqueness plays an important role, as we will discuss further below. Observe that this assumption is considerably weaker than an assumption that there is a unique equilibrium of the $I$-player game. Using familiar arguments (see, for example, Tirole 1988, section 5.7.1.2), if each firm's objective function is globally concave, a sufficient condition for conditional uniqueness is that $\left|\Pi_{a_{i}, a_{i}}^{i}\right|>\left|\Pi_{a_{i}, a_{j}}^{i}\right|$ for $i, j=1, \ldots, I$, $i \neq j$. In contrast, to guarantee uniqueness in the $I$-player game, we must verify that for all $i,\left|\Pi_{a_{i}, a_{i}}^{i}\right|>\sum_{i \neq j}\left|\Pi_{a_{i}, a_{j}}^{i}\right|$.

In order to introduce our final assumption, we define a map $T_{j k}: \mathbb{R}^{n} \rightarrow \mathbb{R}^{n}$, that transposes two elements of a vector. Formally, if $\tilde{\mathbf{x}}=T_{j k}(\mathbf{x})$, then $\tilde{x}_{j}=x_{k}, \tilde{x}_{k}=x_{j}$, and for all $i \neq j, k, \tilde{x}_{i}=x_{i}$. Then we have:

Definition 1 Consider a set of I functions, $f^{i}: \times_{i} X_{i} \rightarrow \mathbb{R}$ for $i=1, . .$, . The functions are exchangeable if for all $i, j, k \in\{1, . ., I\}$ such that $i \neq j \neq k \neq i$, the following two conditions hold: $f^{i}(\mathbf{x})=f^{j}\left(T_{i j}(\mathbf{x})\right) ; f^{i}(\mathbf{x})=f^{i}\left(T_{j k}(\mathbf{x})\right)$.

Using this definition, we can state the assumption:

The firms' profit functions are exchangeable.

$(\mathrm{EXCH})$

This assumption will be maintained throughout the paper. Exchangeability requires a kind of symmetry in the identities of firms: each firm $i$ cares only about the actions and state variables of its opponents, but not about the match between an opponent's identity and actions/state variables. It implies that firm $i$ 's profits are the same as firm $j$ 's profits would be if firm $j$ was in firm $i$ 's situation. It further implies that firm $i$ 's profits are unchanged if the actions and state variables of two opponents are exchanged. Intuitively, when exchangeability holds all differences among firms are summarized in the state variables.

We will provide explicit examples that fit into this framework in Section 4; in general, however, the assumption is consistent with models of Cournot oligopoly, vertical product differentiation, and differentiated product models where the cross-price effects are identical for all firms. What is ruled out by this assumption? Consider a simple example. Firms are horizontally differentiated on a Hotelling line, and each firm can invest to decrease its 
marginal cost. Then, firm $i$ 's profit will depend on whether a near neighbor or a distant firm lowers its marginal cost. Hence, for $I>2$ firms, exchangeability will not hold in a Hotelling framework. For $I=2$ firms, exchangeability will only hold when firms are restricted to locate symmetrically around the midpoint of the interval. ${ }^{14}$

Exchangeability can also be understood in relation to the concept of anonymity, as used in cooperative game theory and social choice theory. This literature considers allocations among a group of agents. A welfare function $w(\mathbf{x})$ is anonymous if an allocation $\mathbf{x}$ yields the same welfare as $T_{j k}(\mathbf{x})$; and a social choice function (mapping agent state variables, or preferences, to allocations) is anonymous if permuting the state variables of two agents leads to a permutation of the allocations (see, for example, Moulin (1988)). Now consider stating the exchangeability assumption in this context. The first requirement of exchangeability is that in terms of firm $i$ 's profits, opposing firms $j \neq i$ are anonymous; the second requirement is that the vector of profit functions, which can be viewed as a single social welfare function mapping state variables and actions to "allocations" of utility, is anonymous.

\section{Dominance results}

In this section, we study conditions under which firms with higher state variables make higher investments in equilibrium. In such cases, we speak of weak increasing dominance. We begin by introducing an abstract theorem that applies to games with strategic substitutes. We then apply the theorem to our model under the assumption that firms are myopic. For the case where investments take place prior to product market competition, we further explore the conditions on the oligopoly model that lead to both weak and strong increasing dominance, so that leading firms increase their market share over time. Finally, we consider the case where firms are far-sighted.

\footnotetext{
${ }^{14}$ Of course, we could consider each firm's horizontal location as a state variable, but this approach will not be useful for our purposes.
} 


\subsection{Ranking Equilibrium Actions in Games with Strategic Sub- stitutes}

As we will see in more detail below, many oligopolistic investment games are games with strategic substitutes, in the sense that firm $i$ 's incentive to invest is decreasing in the level of firm $j$ 's investment. In this section, we introduce a new comparative statics result for games with strategic substitutes. To do so, we introduce a slightly more abstract notation.

Consider a game between $I$ players. Denote player $i$ 's strategy space by $\mathcal{X}_{i}$, with typical element $x_{i}$. Let $\mathcal{X}_{i}=\mathcal{X}_{j}$ for all $i, j$. Assume that $\mathcal{X}_{i}$ is a product set in $\mathbb{R}^{N}, N \leq \infty$ (we allow this generality so that we can analyze dynamic games as well as static ones), ${ }^{15}$ and let $\mathcal{X}=\times_{i} \mathcal{X}_{i}$. For each player, there is an exogenous "state variable," $\theta_{i} \in \Theta_{i}$, where $\Theta_{i}$ is a product set in $\mathbb{R}^{m}$, and $\boldsymbol{\theta}=\left(\theta_{1}, . ., \theta_{I}\right)$ and $\Theta=\times_{i} \Theta_{i}$. Let the players' utility functions be given by $u^{i}: \mathcal{X} \times \Theta \rightarrow \mathbb{R}$.

We will typically assume that the utility functions are exchangeable (as functions of $(\mathbf{x}, \boldsymbol{\theta}))$. Further, we require that:

For each $\boldsymbol{\theta}$, there exists a conditionally unique equilibrium,

where the term "conditionally unique" was defined in Section 2.

Before proceeding, we introduce an important definition (Topkis, 1978).

Definition 2 Let $\mathcal{X}, \mathcal{Y}$ be partially ordered sets. A function $f: \mathcal{X} \times \mathcal{Y} \rightarrow \mathbb{R}$ satisfies increasing differences in $(x ; y)$ if for all $x^{H}>x^{L}, y^{H}>y^{L}$,

$$
f\left(x^{H}, y^{H}\right)-f\left(x^{L}, y^{H}\right) \geq f\left(x^{H}, y^{L}\right)-f\left(x^{L}, y^{L}\right) .
$$

If $\mathcal{Y}=\times_{i} \mathcal{Y}_{i}$ is a product set, $f: \mathcal{Y} \rightarrow \mathbb{R}$ is supermodular in $\mathbf{y}$ if it satisfies increasing differences in $\left(y_{i} ; y_{j}\right)$ for all $i \neq j$.

If $f: \mathbb{R}^{2} \rightarrow \mathbb{R}$ is smooth, it has increasing differences if and only if $f_{x y} \geq 0$.

To begin, we state a condition that applies when the players have multi-dimensional choice sets (such as when they play a dynamic game and choose a series of investments): for

\footnotetext{
${ }^{15}$ Everything we do in this section can be rephrased for the case where $\mathcal{X}_{i}$ is an arbitrary lattice, but the added generality is not required for this paper.
} 
all $\boldsymbol{\theta}$ and all $\mathbf{x}_{-i}$

$$
u^{i}\left(x_{i}, \mathbf{x}_{-i} ; \boldsymbol{\theta}\right) \text { is supermodular in } x_{i}
$$

Condition (OSPM) requires that each player's payoffs are supermodular in her own choice vector. If the choice set is multidimensional, this assumption requires that each component of the player's choice vector is complementary with the other components of the choice vector.

Games with strategic substitutes can be usefully contrasted against games with strategic complementarities. ${ }^{16}$ Games with strategic complementarities are defined by the requirement that each $u^{i}$ satisfies increasing differences in $\left(x_{i} ; x_{j}\right)$ for all $i \neq j$. The following result is due to Topkis (1979).

Lemma 3 Suppose that: (i) (OSPM) holds; (ii) the players' actions are strategic complements, and (iii) $u^{i}$ has increasing differences in $\left(x_{i} ; \theta_{j}\right)$ for all $j$. For each $\boldsymbol{\theta}$, let $\mathbf{x}^{*}(\boldsymbol{\theta})$ be the highest equilibrium. Then, $\boldsymbol{\theta}^{H}>\boldsymbol{\theta}^{L}$ implies $\mathbf{x}^{*}\left(\boldsymbol{\theta}^{H}\right) \geq \mathbf{x}^{*}\left(\boldsymbol{\theta}^{L}\right)$.

The intuition behind this comparative statics result is fairly straightforward. Consider increasing $\theta_{j}$, and suppose this change directly affects only firm $j$, by increasing her incremental returns to investing in the sense defined by Lemma 3. If opponents' actions were held fixed, firm $j$ would want to increase her action. However, such a change would lead all opponents to desire increases in their actions. Since such increases are mutually reinforcing in games of strategic complementarity, the equilibrium action vector must go up.

Now consider a game with strategic substitutes, defined by the requirement that each $u^{i}$ satisfies increasing differences in $\left(x_{i} ;-x_{j}\right)$ for $j \neq i$; that is, any increase in any opponent's action decreases the incremental return to a player's own action: $u^{i}$ has increasing differences in $\left(x_{i} ;-x_{-i}\right)$. For such games, we consider parameters $\theta_{i}$ such that $u^{i}$ has increasing differences in $\left(x_{i} ; \theta_{i}\right)$, as before, but now we suppose that increases in any opponent's state variable decrease the incremental return to acting, that is, $u^{i}$ has increasing differences in $\left(x_{i} ;-\theta_{-j}\right)$ for all $j \neq i$. Then, we have:

Theorem 4 Suppose there are only two players, that (UNQ) holds, and that the payoff functions are exchangeable. Suppose that: (i) (OSPM) holds; (ii) the players' actions are

\footnotetext{
${ }^{16}$ See Bulow, Geanakoplos, and Klemperer (1985) and Fudenberg and Tirole (1984) for more discussion of this distinction in oligopoly games.
} 
strategic substitutes, and (iii) $u^{i}$ has increasing differences in $\left(x_{i} ; \theta_{i}\right)$ and $\left(x_{i} ;-\theta_{j}\right)$ for $j \neq i$. Then $\theta_{i}>\theta_{j}$ implies that $x_{i}^{*}(\theta) \geq x_{j}^{*}(\theta)$.

Proof. Define $\tilde{x}_{1}=x_{1}, \tilde{x}_{2}=-x_{2}, \tilde{\theta}_{1}=\theta_{1}, \tilde{\theta}_{2}=-\theta_{2}$, and let $\tilde{u}^{i}(\tilde{x}, \tilde{\theta})=u^{i}\left(\tilde{x}_{1},-\tilde{x}_{2} ; \tilde{\theta}_{1},-\tilde{\theta}_{2}\right)$ for $i=1,2$. Then the modified game satisfies the conditions of Lemma 3. For a given, $\tilde{\boldsymbol{\theta}}$, let $\tilde{\mathbf{x}}^{*}(\tilde{\boldsymbol{\theta}})$ be the equilibrium of this game. Now, we compare two alternative parameter vectors. In the first vector, $\theta_{1}=\theta_{H}>\theta_{L}=\theta_{2}$. In the second vector, $\theta_{1}=\theta_{L}$; $\theta_{2}=\theta_{H}$. Hence, for the first vector, $\left(\tilde{\theta}_{1}, \tilde{\theta}_{2}\right)=\left(\theta_{H},-\theta_{L}\right)$, whereas for the second vector, $\left(\tilde{\theta}_{1}, \tilde{\theta}_{2}\right)=\left(\theta_{L},-\theta_{H}\right)$. As $\left(\theta_{H},-\theta_{L}\right) \geq\left(\theta_{L},-\theta_{H}\right)$, and since (UNQ) implies that the equilibrium for each parameter vector is unique, Lemma 3 implies that $\tilde{x}_{1}^{*}\left(\theta_{H},-\theta_{L}\right) \geq \tilde{x}_{1}^{*}\left(\theta_{L},-\theta_{H}\right)$ and hence $x_{1}^{*}\left(\theta_{H}, \theta_{L}\right) \geq x_{1}^{*}\left(\theta_{L}, \theta_{H}\right)$. By exchangeability $x_{2}^{*}\left(\theta_{H}, \theta_{L}\right)=x_{1}^{*}\left(\theta_{L}, \theta_{H}\right)$ and hence the result follows.

The proof proceeds by observing that, by re-ordering the action set and state variable for one player, it is possible to convert the two-player game with strategic substitutes to a game with strategic complementarities. ${ }^{17}$ Then, the comparative statics result for games with strategic complementarities, Lemma 3, can be used to compare the equilibrium choices under two scenarios: one where the first player's state variable is higher than the second player's, and one where the roles of the players are reversed. Lemma 3 implies that decreasing the first player's state variable and increasing the second firm's state variable decreases the equilibrium choice for firm one, and increases the equilibrium choice for firm two. Finally, we exploit exchangeability: the equilibrium in the second case is merely the equilibrium of the first case, with the roles of the players reversed. Since reversing the state variables of the players leads to an equilibrium with a lower choice for player 1 and a higher choice for player 2 , we conclude that the player with the higher state variable chooses a higher action. ${ }^{18}$

Now consider extending this result to more than two players. Here, we run into a difficulty. In a game with many players, even if the conditions of Theorem 4 hold, an increase in $\theta_{i}$ does not necessarily lead to an increase in $x_{i}$ and a decrease in the choices of all opponents.

\footnotetext{
${ }^{17}$ Vives (1990) and Amir (1994) use a similar approach to analyze Cournot oligopoly using the tools of supermodular games.

${ }^{18}$ To see the role of the condition (UNQ), suppose that actions are chosen from $\{0,1\}$. If (UNQ) fails, both $(0,1)$ and $(1,0)$ can be equilibria for a given set of parameters. In fact, both might be equilibria for both parameter vectors $\left(\theta_{H}, \theta_{L}\right)$ and $\left(\theta_{L}, \theta_{H}\right)$; this is fully consistent with our assumption that actions are strategic substitutes. Clearly, however, the equilibrium $(0,1)$ when the parameter vector is $\left(\theta_{H}, \theta_{L}\right)$ violates the conclusion of the theorem.
} 
Consider the intuition. Clearly the direct effect of $\theta_{i}$ supports the specified changes in the choice vectors, and one set of indirect effects does as well: when player $i$ increases her action, all opponents have a lower incremental return to their actions. The problem is that a second set of indirect effects may dominate: when player $j$ decreases her action, player $k$ has an incentive to increase his. Whether player $k$ is more sensitive to a change in player $i$ 's action or player $j$ 's action depends on the functional form.

Given that comparative statics results are quite subtle in games with strategic substitutes and more than two players, the existing literature often imposes a number of simplifying assumptions. For example, it is common to consider two-firm models, or to assume that a firm's profit depends only on the sum of opponent actions (as in a Cournot model with perfect substitutes), so that the game effectively becomes a two-player game. These properties have been exploited in the existence proof of Selten (1970), and in the comparative statics discussion of Dixit (1986). However, these assumptions are restrictive, for example ruling out models with imperfect substitutes.

Thus motivated, we now introduce a new result for games with strategic substitutes. Although we cannot generalize the comparative statics results of Lemma 3, we can still provide sufficient conditions for weak increasing dominance. The critical assumption for our result is exchangeability.

Theorem 5 Suppose the assumptions of Theorem 4 hold, except there are $I \geq 2$ players. Then $\theta_{i}>\theta_{j}$ implies that $x_{i}^{*}(\boldsymbol{\theta}) \geq x_{j}^{*}(\boldsymbol{\theta})$.

Proof. Without loss of generality, consider players 1 and 2, and suppose $\theta_{1}>\theta_{2}$. Let $\hat{\boldsymbol{\theta}}=T_{12}(\boldsymbol{\theta})$. By our exchangeability assumption, there exists an equilibrium $\mathbf{x}^{*}(\hat{\boldsymbol{\theta}})$ such that $\mathbf{x}_{-12}^{*}(\boldsymbol{\theta})=\mathbf{x}_{-12}^{*}(\hat{\boldsymbol{\theta}})$. Fix $\mathbf{x}_{-12}=\mathbf{x}_{-12}^{*}(\boldsymbol{\theta})$ and consider the game between players 1 and 2. Let $\mathbf{x}^{* *}(\boldsymbol{\theta})$ and $\mathbf{x}^{* *}(\hat{\boldsymbol{\theta}})$ be equilibria of the two-player game, and observe that (UNQ) implies that each of these equilibria is unique given the parameters. By our exchangeability assumption, players $3, . ., I$ are not affected by the reversal of the state variables of firms 1 and 2. Thus, the equilibrium of the two-player game is also an equilibrium when players $3, . ., I$ are not constrained: $\mathbf{x}^{* *}(\boldsymbol{\theta})=\left(x_{1}^{*}(\boldsymbol{\theta}), x_{2}^{*}(\boldsymbol{\theta})\right)$ and likewise for $\hat{\boldsymbol{\theta}}$. But Theorem 4 implies that $x_{1}^{* *}(\boldsymbol{\theta}) \geq x_{2}^{* *}(\boldsymbol{\theta})$.

The intuition behind the result can be easily related. Our goal is to compare the equilibrium choices for two vectors of state variables: the original vector, and a vector with 
the first two elements transposed. The key insight is that players three and higher are not affected when we reverse the roles of the first two players. Further, transposing the state variables of the first two players should merely transpose their equilibrium choices. Thus, we can proceed by holding fixed the actions of players three and higher at the equilibrium values for the original vector of state variables, and analyze the game between the first two players. But then, the logic of Theorem 4 applies: decreasing player 1's state variable and increasing player 2's state variable decreases the equilibrium choice of player 1 and increases the equilibrium choice of player 2 .

Thus, we see the critical role played by exchangeability: it gives us just enough structure to hold fixed the behavior of players three and higher, and focus on the two-player game. Without this assumption, we could find a counter-example. Such an example might exploit asymmetries in the extent to which one player cares about the choices of the others.

Theorem 5 can potentially be applied in a wide variety of oligopoly problems, as discussed below, as well as in a variety of other economic contexts; Section 4.4 considers a model of strategic trade, while the conclusion discusses a potential application to tournaments.

It is instructive to compare the approach pursued here with more standard approaches that might be used to reach the conclusion $\theta_{i}>\theta_{j} \Longrightarrow x_{i}^{*}(\boldsymbol{\theta}) \geq x_{j}^{*}(\boldsymbol{\theta})$. Consider an alternative set of sufficient conditions: (a) $\theta_{i}=\theta_{j} \Longrightarrow x_{i}^{*}(\boldsymbol{\theta})=x_{j}^{*}(\boldsymbol{\theta})$, and (b) $x_{i}^{*}(\theta)$ is weakly increasing in $\theta_{i}$ and $x_{j}^{*}(\theta)$ is weakly decreasing in $\theta_{i}$ for $j \neq i$. If a particular game satisfies the requisite regularity conditions, condition (b) could be verified using the implicit function theorem. This approach would differ from ours in two respects. First, it would require additional (dominant-diagonal) conditions on second derivatives. Second, unlike the conditions of Theorem 5, (b) excludes situations where an increase in $\theta_{i}$ leads to an increase of some $x_{j}^{*}(\boldsymbol{\theta}), j \neq i$, even though such situations are quite plausible in games with strategic substitutes. Indeed, when there are three or more players, it is possible to construct examples where the conditions of Theorem 5 hold but condition (b) fails. Thus, by imposing exchangeability, we are able to dispense with smoothness requirements, dominant diagonal conditions on second derivatives, and we are able to include a range of economic behaviors excluded by (b). Further, as discussed in Section 2, even our maintained assumption of essential uniqueness is weak compared to the global dominant diagonal condition. 


\subsection{Weak Increasing Dominance for Myopic Firms}

Using the results of the last subsection, we now give conditions for weak increasing dominance in our investment game, when firms are myopic.

Proposition 6 Suppose firms are myopic. Suppose that for all $i \neq j$, all $\mathbf{a}$ and all $\mathbf{Y}$,

$$
\Pi_{a_{i}, a_{j}}^{i}=\left(E \pi^{i}\right)_{a_{i}, a_{j}} \leq 0, \Pi_{a_{i}, Y_{i}}^{i}=\left(E \pi^{i}\right)_{a_{i}, Y_{i}}-k_{a_{i}, Y_{i}}^{i} \geq 0, \Pi_{a_{i}, Y_{j}}^{i}=\left(E \pi^{i}\right)_{a_{i}, Y_{j}} \leq 0 .
$$

Then, weak increasing dominance holds: for a given $i \neq j$, if firm $i$ has a higher state variable, the equilibrium investment of firm $i$ is greater than that of firm $j$, that is, $Y_{i}>Y_{j}$ implies $a_{i}^{*}(\mathbf{Y}) \geq a_{j}^{*}(\mathbf{Y})$.

The Proposition is a direct application of Theorem 5. The conditions of the Proposition can be understood as follows. First, in terms of adjustment costs, the incremental cost of investment must not increase too rapidly as the own state variable increases. The remaining conditions concern expected product market profits. For future reference, we summarize the conditions that would be required to satisfy (WID) in the absence of adjustment costs:

$$
\left(E \pi^{i}\right)_{a_{i}, a_{j}} \leq 0, \quad\left(E \pi^{i}\right)_{a_{i}, Y_{i}} \geq 0, \text { and }\left(E \pi^{i}\right)_{a_{i}, Y_{j}} \leq 0 .
$$

In words, (WID-P) requires that in terms of expected product market profits, the investments of the two firms are strategic substitutes; higher levels of a firm's own state variable increase the marginal returns to investment; and higher levels of the opponent's state variable decrease the marginal returns to investment. In Section 4, we will further analyze these conditions in the context of oligopoly models.

Of course, not all applications will be characterized by weak increasing dominance. Indeed, the following simple corollary gives sufficient conditions for "weak decreasing dominance," meaning that leaders invest less than laggards:

Corollary 7 Suppose firms are myopic. Suppose that for all $i \neq j$ and all $(\mathbf{a}, \mathbf{Y})$,

$$
\Pi_{a_{i}, a_{j}}^{i} \leq 0, \Pi_{a_{i}, Y_{i}}^{i} \leq 0, \text { and } \Pi_{a_{i}, Y_{j}}^{i} \geq 0 .
$$

Then, $Y_{i}>Y_{j}$ implies $a_{i}^{*}(\mathbf{Y}) \leq a_{j}^{*}(\mathbf{Y})$.

In words, if a higher state variable for firm $i$ decreases firm $i$ 's investment incentives and increases firm $j$ 's investment incentives, the leading firm will invest less if the firms are myopic. 


\subsection{Investments that Precede Product Market Competition}

In this section, we further explore the special case where the firms invest prior to product market competition, and thus the profits in the product market can be represented as reduced-form functions of the state variables, as in (2). Our goal is to analyze the conditions under which (WID-P) is satisfied. When (2) holds, we have the following (where, as usual, the subscripts on $\pi$ and $\widehat{\pi}^{i}$ denote partial derivatives):

$$
\begin{aligned}
& \pi_{Y_{i}, y_{i}}^{i}\left(\mathbf{a}^{t}, \mathbf{y}^{t}, \mathbf{Y}^{t-1}\right)=\widehat{\pi}_{Y_{i}, Y_{i}}^{i}\left(\mathbf{Y}^{t-1}+\mathbf{y}^{t}\right) \\
& \pi_{Y_{j}, y_{i}}^{i}\left(\mathbf{a}^{t}, \mathbf{y}^{t}, \mathbf{Y}^{t-1}\right)=\pi_{y_{i}, y_{j}}^{i}\left(\mathbf{a}^{t}, \mathbf{y}^{t}, \mathbf{Y}^{t-1}\right)=\widehat{\pi}_{Y_{i}, Y_{j}}^{i}\left(\mathbf{Y}^{t-1}+\mathbf{y}^{t}\right)
\end{aligned}
$$

When investment returns are deterministic, $\mathbf{a}^{t}=\mathbf{y}^{t}$, and (2) holds, $E \pi^{i}\left(\mathbf{a}^{t}, \mathbf{Y}^{t-1}\right)=\widehat{\pi}^{i}\left(\mathbf{Y}^{t-1}+\right.$ $\mathbf{a}^{t}$ ), so that (5) describes the interactions among investments and between investments and state variables. In this case, the following condition will be sufficient to guarantee that (WID-P) holds:

$$
\widehat{\pi}_{Y_{i}, Y_{i}}^{i} \geq 0 \text { and } \widehat{\pi}_{Y_{i}, Y_{j}}^{i} \leq 0 .
$$

Next, we analyze (WID-O) in terms of a more primitive (but still reduced-form) oligopoly model. Bagwell and Staiger (1994) argued that a wide range of oligopoly models have the feature that investments in cost-reduction are strategic substitutes. To see why such a result might hold in general, suppose that $\widehat{\pi}^{i}\left(\mathbf{Y}^{t}\right)=D^{i}\left(\mathbf{Y}^{t}\right) \cdot m^{i}\left(\mathbf{Y}^{t}\right)$, where $D^{i}\left(\mathbf{Y}^{t}\right)$ is the demand for firm $i$ and $m^{i}\left(\mathbf{Y}^{t}\right)$ is the markup in the product market equilibrium when the state variable is $\mathbf{Y}^{t}$. Observe that:

$$
\widehat{\pi}_{Y_{i}, Y_{j}}^{i}=\frac{\partial D^{i}}{\partial Y_{i}^{t}} \frac{\partial m^{i}}{\partial Y_{j}^{t}}+\frac{\partial D^{i}}{\partial Y_{j}^{t}} \frac{\partial m^{i}}{\partial Y_{i}^{t}}+m^{i} \frac{\partial^{2} D^{i}}{\partial Y_{i}^{t} \partial Y_{j}^{t}}+D^{i} \frac{\partial^{2} m^{i}}{\partial Y_{i}^{t} \partial Y_{j}^{t}}
$$

Here, the first two terms on the right-hand side are typically negative. To understand the first term, observe that in many applications, improvements in the opponent's state variable are bad for market share and the markup: $\frac{\partial D^{i}}{\partial Y_{j}^{t}} \leq 0$ and $\frac{\partial m^{i}}{\partial Y_{j}^{t}} \leq 0$. Then, the negative effect of a competitor's improvement on a firm's own mark-up has greater effects on profits the higher one's own state, and hence the higher the firm's own demand $\left(\frac{\partial D^{i}}{\partial Y_{i}^{t}} \frac{\partial m^{i}}{\partial Y_{j}^{t}} \leq 0\right)$. To understand the second term, note that the positive effect of a firm's state on its own markup has greater effect on profits the lower the competitor's state and hence the higher one's 
demand $\left(\frac{\partial D^{i}}{\partial Y_{j}^{t}} \frac{\partial m^{i}}{\partial Y_{i}^{t}} \leq 0\right)$. Similarly,

$$
\widehat{\pi}_{Y_{i}, Y_{i}}^{i}=2 \frac{\partial D^{i}}{\partial Y_{i}^{t}} \frac{\partial m^{i}}{\partial Y_{i}^{t}}+m^{i} \frac{\partial^{2} D^{i}}{\left(\partial Y_{i}^{t}\right)^{2}}+D^{i} \frac{\partial^{2} m^{i}}{\left(\partial Y_{i}^{t}\right)^{2}}
$$

Recall our initial (defining) assumption that $\frac{\partial D^{i}}{\partial Y_{i}^{t}} \geq 0$; further, since in many applications, a higher $Y_{i}^{t}$ corresponds to factors such as lower costs or higher quality, we expect $\frac{\partial m^{i}}{\partial Y_{i}^{t}} \geq 0$ as well. If so, then $\frac{\partial D^{i}}{\partial Y_{i}^{t}} \frac{\partial m^{i}}{\partial Y_{i}^{t}} \geq 0$. Intuitively, the positive effect on the mark-up that stems from reduced marginal costs (or improved quality) is enhanced by the positive effect of costreduction on demand. So long as neither mark-up nor demand is extremely concave in the own state variable, this effect dominates and (WID-O) holds. Similarly,

The next result follows directly from these arguments:

Lemma 8 Suppose that $D^{i}\left(Y_{1}^{t}, \ldots, Y_{I}^{t}\right)$ and $m^{i}\left(Y_{1}^{t}, \ldots, Y_{I}^{t}\right)$ are linear functions, and that $\partial D^{i} / \partial Y_{i}^{t} \geq 0, \partial m^{i} / \partial Y_{i}^{t} \geq 0, \partial D^{i} / \partial Y_{j}^{t} \leq 0$ and $\partial m^{i} / \partial Y_{j}^{t} \leq 0$. Then Condition WID-O holds.

By Proposition 6, the conditions of Lemma 8 imply that weak increasing dominance will hold if adjustment costs do not increase too rapidly with state variables. Obviously, the linearity assumption is much more special than required. Nevertheless, it can be applied in the following Lemma, which shows that many familiar oligopoly models satisfy the properties summarized in (WID-O).

Lemma 9 In the following models, condition WID-O holds: ${ }^{19}$

(a) Bertrand or Cournot competition where each firm's marginal cost is constant, goods are differentiated, and demand is linear (Dixit, 1979), where $Y_{i}^{t}$ represents either marginal cost, firm $i$ 's quality level, or the difference between the latter two parameters.

(b) Models of horizontal competition on the line (d'Aspremont et al., 1979) or on the circle (Salop, 1979) with quadratic transportation costs, where $Y_{i}^{t}$ is as in (a).

(c) The Shaked/Sutton (1982) model of vertical quality differentiation with potentially different marginal costs, where $Y_{i}^{t}$ represents firm i's marginal cost. ${ }^{20}$

\footnotetext{
${ }^{19}$ Bagwell and Staiger (1994) establish that several of these examples satisfy strategic substitutability. However, they do not discuss convexity.

${ }^{20}$ In this case, condition WID-O does not necessarily hold when $Y_{i}^{t}$ represents firm $i$ 's quality level.
} 
(d) The Shaked/Sutton (1982) model of vertical quality differentiation where the market is assumed to be covered, the firms have identical marginal costs, and $Y_{i}^{t}$ represents firm $i$ 's quality level.

A sketch of the proof can be found in the Appendix. In the first three cases, the result follows from direct application of Lemma 8. The case of vertical differentiation with the quality parameter as the state variable is not quite as straightforward, because the conditions of Lemma 8 do not hold for every model of vertical differentiation: increasing quality does not necessary increase demand and the mark-up, in particular for a low-quality firm that reduces vertical differentiation by moving closer to its rival. ${ }^{21}$

Although Lemma 9 is useful in determining whether (WID-O) holds, in order to apply Proposition 6, it remains to check that the models satisfy our maintained assumptions. In particular, we must verify the assumptions that profits are exchangeable and that there exists a conditionally unique equilibrium. Exchangeability always holds in models (a), (c), and (d), but it requires that we restrict attention to only two firms in model (b), where firms are horizontally differentiated. Even for the two-firm case, when the firms are located on a line, we require the additional assumption that the locations are equidistant from the midpoint of the line. The conditional uniqueness requirement is satisfied if $\Pi_{a_{i}, a_{i}}^{i} \Pi_{a_{j}, a_{j}}^{j}-\Pi_{a_{i}, a_{j}}^{i} \Pi_{a_{j}, a_{i}}^{j} \neq 0$ for $Y_{i} \neq Y_{j}, i \neq j$. In terms of our primitives, this will hold if the adjustment cost function is sufficiently convex in investment.

If investment is deterministic and $y_{i}^{t}=a_{i}^{t}$, we conclude that product market competition creates strong forces in favor of the result that leading firms have stronger incentives to increase their state variable than lagging firms.

Proposition 10 Suppose that firm investments precede product market competition, that investment returns are deterministic, and that $y_{i}^{t}=a_{i}^{t}$. Suppose further that product market competition is described by one of the models of Lemma 9, or that the conditions of Lemma 8 are satisfied. Finally, assume that $\hat{\pi}_{Y_{i}, Y_{i}}^{i} \geq k_{a_{i}, Y_{i}}^{i}$ for all $(\mathbf{a}, \mathbf{Y})$. Then weak increasing dominance holds for myopic firms.

\footnotetext{
${ }^{21}$ Indeed, Ronnen (1991) considers the Shaked/Sutton model when the market is not covered, and finds conditions whereby vertical investments are strategic complements; similarly, the conditions do not necessarily hold if the firms have different marginal cost parameters. See also Ellickson (1999) for an example where quality investments may be strategic substitutes or complements depending on the parameter values.
} 
In Section 4, we will consider specific models that fit into our general framework, and further explore stochastic investment. We will also highlight circumstances under which countervailing effects are likely to dominate over the forces identified in this section. Before proceeding, however, we consider conditions under which leading firms will not only choose higher investments, but will also increase their market shares over time.

\subsubsection{Strong Increasing Dominance}

Weak increasing dominance does not necessarily imply strong increasing dominance, that is, that leading firms will increase their market share over time. Clearly, stronger investments need not necessarily imply faster growth of the state variable if there is a stochastic relation between investment and investment success. ${ }^{22}$ However, even if the state variable of the leading firm grows faster than the others, additional conditions are required for weak increasing dominance to imply strong increasing dominance.

We continue to focus on the case where investment is deterministic $\left(\mathbf{y}^{t}=\mathbf{a}^{t}\right)$, investment takes place before product market competition, and $\widehat{\pi}^{i}(\mathbf{Y})=D^{i}(\mathbf{Y}) \cdot m^{i}(\mathbf{Y})$. It is straightforward to show that under these assumptions a firm that increases its state variable faster than its competitors can increase its market share if and only if (letting $D$ be total demand): $:^{23}$

$$
D \sum_{k=1}^{I} \frac{\partial D^{i}}{\partial Y_{k}}-D^{i} \sum_{k=1}^{I} \sum_{j=1}^{I} \frac{\partial D^{j}}{\partial Y_{k}} \geq 0
$$

To interpret this condition, consider a special case: demand functions are linear in states and symmetric, so that there exist two constants, $K_{1}$ and $K_{2}$, such that for all $i, j, \partial D^{i} / \partial Y_{i}=$ $K_{1}$ and $\partial D^{i} / \partial Y_{j}=K_{2}$. In this case, (8) becomes $1 / I \geq(\leq) D^{i} / D$ for $\sum_{k=1}^{I} \sum_{j=1}^{I} \frac{\partial D^{j}}{\partial Y_{k}} \geq(\leq) 0$. Since the leading firm by definition has a market share greater than $1 / I$, strong increasing dominance holds if and only if $\sum_{k=1}^{I} \sum_{j=1}^{I} \frac{\partial D^{j}}{\partial Y_{k}} \leq 0$. As this last term describes the growth of total market demand if every firm can increase its state variable by the same marginal amount, the interpretation is straightforward. Weak increasing dominance implies strong increasing dominance if and only if market demand remains unaffected or shrinks as a result of a simultaneous increase in all state variables.

\footnotetext{
${ }^{22}$ Also, consider the discussion of learning-by-doing below.

${ }^{23}$ The claim follows by taking the sum of derivatives of firm $i$ 's profit over $i=1, \ldots, I$ and rearranging.
} 
Of course, these are cases where the investments only have demand-stealing rather than demand-creating effects. Other things being equal, we should therefore expect strong increasing dominance to be more typical, say, for advertising investments in a mature industry than for cost-reducing investments in products with fairly elastic demand.

\subsection{Far-Sighted Firms}

Now suppose that firms discount the future at rate $\delta>0$. We wish to generalize Proposition 6 to the case where firms look forward to the future, maximizing present discounted expected profits. We assume that the actions of firms are observable in every period. However, to simplify matters, we will assume that the evolution of the state variable is deterministic.

To begin, we show that we are able to provide powerful conclusions when we restrict attention to the benchmark case of "open-loop" pure strategy Nash equilibria (OPSNE). In an OPSNE, each firm makes a deterministic investment plan at the beginning of the game, and this plan cannot be modified later; the investment plans of the firms must best responses to one another when considered at date 0 . While in general, such a restriction can be severe, it is less so in the deterministic context: every OPSNE is also a Nash equilibrium in the game where each player can condition his actions on the observed history of past play, though it may not be subgame-perfect (see Fudenberg and Tirole (1991), pp. 130-133). ${ }^{24}$ As the OPSNE omits the strategic effects that might arise when firms attempt to manipulate the future investments of opponents, it serves as a useful point of comparison. Further, if firms are fairly impatient and must fix their investment plans several periods in advance, OPSNE may provide a good first approximation of behavior. Such advance planning might be required if research and development requires large capital expenditures or specialized technology, such as laboratories.

Milgrom and Roberts (1990) showed that an advantage of the lattice-theoretic approach to games is that the theory of supermodular games can be applied to problems with a wide variety of choice sets, including problems where the agent chooses an infinite sequence of

\footnotetext{
${ }^{24}$ To see this, suppose that $\overrightarrow{\mathbf{a}}^{O}$ is an open-loop NE. Then, consider the unrestricted game, where players can condition their investment in period $t$ on the history of play up to period $t$. Suppose that player $i$ chooses a strategy where his action at every step depends only on $t$ and $\mathbf{Y}^{0}$, but not on any other aspect of the history. Suppose in particular, player $i$ 's plan is to use $\overrightarrow{\mathbf{a}}^{i, O}$. Then, the same conditions that guarantee that $\overrightarrow{\mathbf{a}}^{O}$ is an OPSNE imply that $\overrightarrow{\mathbf{a}}^{j, O}$ is a best response to $\overrightarrow{\mathbf{a}}^{i, O}$ for $j \neq i$. This argument breaks down if the game is stochastic or firms use mixed strategies.
} 
actions. They apply the theory of supermodular games to analyze OPSNE of infinite-horizon dynamic games. The following Proposition uses a similar approach, applying Theorem 5 to the infinite-horizon problem.

Proposition 11 Suppose that firms live for $T \leq \infty$ periods and are far-sighted, and that (WID) holds. Suppose further that the evolution of the state variable is deterministic and satisfies $Y_{i}^{t}=Y_{i}^{t-1}+a_{i}^{t}$, and that for all $i \neq j$, and all $(\mathbf{a}, \mathbf{Y})$,

$$
\left(E \pi^{i}\right)_{Y_{i}, Y_{i}} \geq 0, \quad\left(E \pi^{i}\right)_{a_{j}, Y_{i}} \leq 0, \text { and }\left(E \pi^{i}\right)_{Y_{i}, Y_{j}} \leq 0 .
$$

If there is a conditionally unique OPSNE, denoted $\overrightarrow{\mathbf{a}}^{*}\left(\mathbf{Y}^{0}\right), Y_{i}^{0}>Y_{j}^{0}$ implies that for all $t$, $a_{i}^{t *}\left(\mathbf{Y}^{0}\right) \geq a_{j}^{t *}\left(\mathbf{Y}^{0}\right)$.

The proof is given in the Appendix. Proposition 11 imposes several conditions beyond those required in Proposition 6. The functional restriction on the evolution of the state variable simplifies the problem, allowing us to consider directly the effect of today's action on all future periods. Condition (WID-D1) is required to guarantee that the following additional conditions hold: the actions of a given firm in two different periods are complementary in increasing the profit in all future periods (requiring the additional assumption $\prod_{Y_{i}, Y_{i}}^{i} \geq 0$ ); and, across any pair of periods, the actions of the two firms are strategic substitutes (requiring the additional assumptions $\Pi_{a_{j}, Y_{i}}^{i} \leq 0$ and $\left.\Pi_{Y_{i}, Y_{j}}^{i} \leq 0\right)$. Since firm $j$ 's actions and states do not affect firm $i$ 's adjustment costs, the conditions reduce to restrictions on the expected product market profits.

Consider the special case where investment precedes product market competition. Then, the restriction analyzed in the last subsection, (WID-O), implies both (WID) and (WID-D1).

Our restriction to OPSNE in Proposition 11 is potentially severe. While it illustrates that some aspects of dynamic competition reinforce our results about increasing dominance, the result ignores the incentives of firms to adjust their investment strategies over time in an attempt to manipulate the investment response of opposing firms. Unfortunately, when we enlarge the strategy space of firms in the dynamic game to allow them to respond to current conditions, a variety of competing effects can emerge. The following result highlights a set of sufficient conditions for weak increasing dominance in a dynamic game between two firms. 
Proposition 12 Suppose the assumptions of Proposition 11 hold. In addition, assume that in each period, each firm's investment is chosen from a compact subset of $\mathbb{R}$, and that in each period, the opponent's equilibrium action induces a unique, interior best-response investment. Finally, assume that either (1) the conditions of Lemma 8 hold, or, more generally, (2) $\Pi^{i}$ is twice continuously differentiable, and for $i \neq j$ and for all $(\mathbf{a}, \mathbf{Y})$,

$$
\left(E \pi^{i}\right)_{Y_{j}, Y_{j}} \geq 0 ; \quad\left(E \pi^{i}\right)_{Y_{j}, a_{j}} \geq 0 ; \quad\left(E \pi^{i}\right)_{a_{j}, a_{j}} \geq 0 ; \quad\left(E \pi^{i}\right)_{a_{j}} \leq 0
$$

and for all $t, a_{j}^{t}\left(\mathbf{Y}^{t-1}\right)$ is continuously differentiable, and

$$
\frac{\partial}{\partial Y_{i}^{t}} a_{j}^{t}\left(\mathbf{Y}^{t}\right) \text { is nondecreasing in }\left(-Y_{i}^{t}, Y_{j}^{t}\right) \text {, and } \frac{\partial}{\partial Y_{j}^{t}} a_{j}^{t}\left(\mathbf{Y}^{t}\right) \text { is nonincreasing in } Y_{j}^{t} \text {. }
$$

If there is a conditionally unique Markov-perfect equilibrium, where strategies in period $t$ are denoted $a^{t *}(\mathbf{Y})$, then $Y_{i}^{t-1}>Y_{j}^{t-1}$ implies that $a_{i}^{t *}\left(\mathbf{Y}^{t-1}\right) \geq a_{j}^{t *}\left(\mathbf{Y}^{t-1}\right)$.

This result provides sufficient conditions for weak increasing dominance in a Markovperfect equilibrium, whereby each firm's investment in period $t$ depends on the state variable in period $t$. Under the assumptions of Proposition 12, we can compare the Markov-perfect equilibrium with the OPSNE, finding that the additional strategic effects reinforce the tendency towards weak increasing dominance. However, when the assumptions are relaxed, the additional strategic effects may serve as mitigating factors. If firms are sufficiently patient, weak increasing dominance may be overturned.

Consider the role of each assumption. First, we maintain the assumption that $T<\infty$ in order to avoid technical issues concerning differentiability of the value function. The results can be extended to an infinite horizon, but the proof is more cumbersome. Differentiability simplifies the analysis by allowing us to apply the envelope theorem when analyzing the interactions between investments across firms and over time.

Second, we have imposed additional conditions on partial derivatives of the product market payoffs (WID-D2) and the policy functions (WID-A). They play a role because, to determine whether investments are strategic substitutes, we must verify that today's investments are substitutes in affecting tomorrow's profit. These restrictions are implied by the conditions of Lemmas 8 and 9. One consequence of condition (WID-A) is that firm $j$ 's 
period- $t$ investment decreases the marginal return to firm $i$ 's period- $t$ investment, through its effect on firm $j$ 's period- $t+1$ investment. When per-period payoffs are quadratic, optimal policy functions are linear, and the latter effect is zero. However, in general, the third derivatives of the value function can potentially generate strategic interaction effects that work against weak increasing dominance.

Now consider the role of the assumption that there are only two firms. The first consequence of this assumption, exploited in the proof, is that equilibrium policy functions will be monotone: by Lemma 3, when firm $i$ has a higher state variable, firm $i$ 's equilibrium investment increases and firm $j$ 's equilibrium investment decreases. Formally, $\frac{\partial}{\partial Y_{i}^{t}} a_{j}^{t}\left(Y^{t}\right) \leq 0$. With more than 2 firms, this conclusions no longer holds, as discussed in Section 4.1. Further, even if equilibrium policy vectors are monotone, competing effects can still arise (for similar reasons). Consider the interaction between firm $i$ 's state variable and firm $j$ 's state variable in the final period. The cross-partial derivative $\frac{\partial^{2}}{\partial Y_{i}^{T} \partial Y_{j}^{T}} \Pi^{i}\left(\mathbf{a}^{T}\left(\mathbf{Y}^{T}\right), \mathbf{Y}^{T}\right)$ includes the following terms:

$$
\Pi_{Y_{i}, a_{k}}^{i}\left(\mathbf{a}^{T}\left(\mathbf{Y}^{T}\right), \mathbf{Y}^{T}\right) \frac{\partial}{\partial Y_{j}^{T}} a_{k}^{T}\left(\mathbf{Y}^{T}\right)+\Pi_{a_{j}, a_{k}}^{i}\left(\mathbf{a}^{T}\left(\mathbf{Y}^{T}\right), \mathbf{Y}^{T}\right) \frac{\partial}{\partial Y_{i}^{T}} a_{j}^{T}\left(\mathbf{Y}^{T}\right) \frac{\partial}{\partial Y_{j}^{T}} a_{k}^{T}\left(\mathbf{Y}^{T}\right)
$$

Notice that if $\frac{\partial}{\partial Y_{j}^{T}} a_{k}^{T}\left(\mathbf{Y}^{T}\right) \leq 0$, the first term is positive, creating a force opposing strategic substitutability between firm $i$ 's investment and firm $j$ 's investment. We have not specified the sign of $\Pi_{a_{j}, a_{k}}^{i}$. Thus, when more than two firms are present, strategic interaction between two firms is complicated by the effects of the two firms' investments on the investments of other firms.

In summary, we find that when firms are forward-looking, the basic forces from our static model remain present; and if the firms are forced to commit to strategic investment plans in advance, our results about weak increasing dominance are reinforced. Thus, our results about weak increasing dominance are perhaps most salient when firms are impatient, or when investment plans are inherently long-term. However, if firms are far-sighted and if they adjust their investments in response to the evolution of the state variable, then our results must be qualified. Competing effects may arise when there are more than two firms, or when the curvature of the profit function is very sensitive to the level of the state variables. ${ }^{25}$

\footnotetext{
${ }^{25}$ Of coures, increasing dominance may arise even when the sufficient conditions of Proposition 12 are not satisfied. For instance, in a model of Cabral (1999), increasing dominance arises despite the fact that expected payoffs are concave in the state variable for leaders and convex for laggards.
} 
Before proceeding, we mention a final comment about our extension to far-sighted firms: our result about decreasing dominance, Corollary 7, cannot be extended to allow for farsighted firms, even under the additional restrictive assumptions outlined above. For example, applying the logic of the proof of Proposition 11 would require that the intertemporal profit function satisfies increasing differences in $\left(a_{i}^{t} ;-a_{j}^{t}\right)$, and in $\left(a_{i}^{t} ; Y_{j}^{t}\right)$ for $i \neq j$. The first

condition generally requires $\Pi_{Y_{i}, Y_{j}}^{i} \leq 0$, whereas the second condition requires $\Pi_{Y_{i}, Y_{j}}^{i} \geq 0$. Intuitively, if firm $j$ 's state variable increases the returns to firm $i$ 's investment in terms of today's profits, then firm $j$ 's investment increases the returns to firm $i$ 's investment in the future. But this violates the requirement that across any pair of periods, the investments of the two firms are strategic substitutes. Thus, if firms are far-sighted, another approach is required to provide conditions under which lagging firms "catch up" to leading firms.

\section{Examples}

In the following, we apply the framework to several specific examples of investment games.

\subsection{Incremental Investment Games}

Several authors (e.g. Flaherty 1980) have considered incremental investment games. ${ }^{26}$ We now introduce a generalized model of incremental investments, allowing for more than two firms, general functional forms for product market competition, and stochastic investment. ${ }^{27}$ We show that increasing dominance holds quite generally in this context, so long as any competing effects from adjustment costs are not too large, and the firms are not too patient.

We interpret $a_{i}^{t}$ as an investment that takes place prior to product market competition, such as a cost-reducing or demand-enhancing investment. The state variable $Y_{i}^{t}$ represents the cumulated cost reduction from some common reference level $\bar{c}$, or else the quality level. Hence, the profit from product market competition can be written as in (2). If investments are deterministic, Proposition 10 applies directly: so long as the marginal cost of adjustment

\footnotetext{
${ }^{26}$ The product life cycle model of Klepper (1996) also incorporates incremental investments; however, that model has a richer structure, as firms take three different kinds of investment decisions.

${ }^{27}$ Flaherty (1980) considers more than two firms, but does not derive general results about weak increasing dominance.
} 
does not increase too fast with a firm's own state variable, and firms are sufficiently shortsighted, increasing dominance should hold.

Two extreme examples of adjustment costs can be used to highlight scenarios under which the conditions on adjustment costs are likely to be satisfied. First, suppose that adjustment costs are entirely independent of the state variable. At the other extreme, there exists a strictly increasing and convex function $\hat{k}^{i}$ such that $k^{i}\left(a_{i}^{t}, Y_{i}^{t-1}\right)=\hat{k}^{i}\left(Y_{i}^{t-1}+a_{i}^{t}\right)=$ $\hat{k}^{i}\left(Y_{i}^{t}\right)$. In words, the adjustment costs depend only on the target level of the state variable, not on the initial state. This type of adjustment cost is likely to arise (at least for $Y_{i}^{t}>$ $\left.\max \left\{Y_{1}^{t-1}, \ldots, Y_{I}^{t-1}\right\}\right)$ if the firm invests in a radically different technology, product variant or organizational form, so that earlier expertise is of little use. In this case, the lower is a firm's state variable, the cheaper it is to attain a given increase in the state variable, $a_{i}^{t}$; thus, the adjustment cost function creates a force that could potentially upset (WID).

Now consider the case of stochastic investments. A model of incremental investment motivates several assumptions about the investment technology. First, assume that the distribution of $y_{i}^{t}$ depends only on firm $i$ 's investment. Further, assume that higher levels of investment lead to a First-Order Stochastic Dominance (FOSD) improvement in the distribution of $y_{i}^{t}$, and that investment returns are distributed independently across firms. ${ }^{28}$ Formally, there exist marginal distribution functions $\hat{H}^{i}\left(y_{i}^{t} \mid a_{i}^{t}\right), i=1, . ., I$, such that:

$$
H\left(\mathbf{y}^{t} \mid \mathbf{a}^{t}, \mathbf{Y}^{t-1}\right)=\prod_{i} \hat{H}^{i}\left(y_{i}^{t} \mid a_{i}^{t}\right), \text { and } \hat{H}^{i}\left(y_{i}^{t} \mid a_{i}^{t}\right) \text { is nonincreasing in } a_{i}^{t} .
$$

Lemmas 8 and 9 provide conditions under which, when investments are deterministic, the payoff functions satisfy condition (WID-O). The following result, proved in the Appendix, indicates that (9) and (WID-O) are sufficient to imply the desired conditions on expected product market profits, (WID-P). For simplicity,we restrict attention to the case of myopic firms; if firms are far-sighted, the game can be analyzed using the approach of Proposition 12.

Proposition 13 In the incremental investment model with stochastic investments, suppose that (WID-O) and (9) hold, and that $\left(E \pi^{i}\right)_{a_{i}, Y_{i}} \geq k_{a_{i}, Y_{i}}^{i}$ for all $\left(a_{i}, Y_{i}\right)$. Then weak increasing dominance holds for myopic firms.

\footnotetext{
${ }^{28}$ In fact, independence is not necessary; see Athey (1999) and Athey and Schmutzler (1995) for a description of the restrictions that would be required on the joint distribution of investment returns to preserve our results.
} 
Our results about incremental investment games can be applied to a variety of industries. Bagwell and Ramey (1994) argue that in the retail sector, leading firms made a variety of costreducing investments as they gained in market share. For example, Wal-Mart invested in its own distribution system, including trucks, warehouses, and a satellite-based communication system, as well as advanced information technology systems to manage its inventory. Sutton (1991) provides a variety of other examples.

\subsubsection{Multi-dimensional investments}

In this section, we show that our results about incremental investment games extend to the case where firms invest in both cost reduction and quality improvement. Recall that Theorem 5 applies to games where the firms make more than one type of investment, provided these investments are complementary; thus, Propositions 6 and 11 can be easily extended to that case. It remains to be verified that the relevant restrictions are satisfied in the incremental investment games.

Cost-reducing and demand-enhancing investments for monopolists have been shown to be complementary under fairly general conditions ${ }^{29}$ now, we generalize that result to an oligopoly setting. Formally, let $\mathbf{Y}_{i}^{t}=\left(Y_{i C}^{t}, Y_{i Q}^{t}\right)$ and let $\mathbf{a}_{i}^{t}=\left(a_{i C}^{t}, a_{i Q}^{t}\right)$. If the adjustment cost functions are additively separable for the two investments and $k_{a_{i}, Y_{i}}^{i}$ is sufficiently small, and further, if for $\eta, \kappa \in\{C, Q\}$,

$$
\frac{\partial^{2}}{\partial Y_{i \eta}^{t} \partial Y_{i \kappa}^{t}} \widehat{\pi}^{i}\left(\mathbf{Y}^{t}\right) \geq 0 \text { and } \frac{\partial^{2}}{\partial Y_{i \eta}^{t} \partial Y_{j \kappa}^{t}} \widehat{\pi}^{i}\left(\mathbf{Y}^{t}\right) \leq 0
$$

then we can apply Propositions 6 and 11 to this game as well. An implication is that, starting from symmetry, if one firm gains an initial advantage in either cost or quality, it will retain this advantage, investing more in both cost-reduction and quality improvement.

To further understand when (WID-O') will be satisfied, observe that we can extend Lemma 8 to allow for both cost-reducing and quality-improving investments. In particular, it is straightforward to show that condition (WID- $\mathrm{O}^{\prime}$ ) holds provided demand and mark-up can be written as linear functions $D^{i}\left(Y_{1 C}^{t}, . ., Y_{I C}^{t} ; Y_{1 Q}^{t}, . ., Y_{I Q}^{t}\right)$ and $m^{i}\left(Y_{1 C}^{t}, . ., Y_{I C}^{t} ; Y_{1 Q}^{t}, . ., Y_{I Q}^{t}\right)$,

\footnotetext{
${ }^{29}$ See Bagwell and Ramey (1994) and Athey and Schmutzler (1995). The driving force behind this result is a scale effect: a low-cost firm will have higher per-unit profit and hence values an increase in demand more than a high-cost firm.
} 
and further, $\partial D^{i} / \partial Y_{i \eta}^{t}>0, \partial m^{i} / \partial Y_{i \eta}^{t}>0, \partial D^{i} / \partial Y_{j \eta}^{t}<0$ and $\partial m^{i} / \partial Y_{j \eta}^{t}<0$ for $\eta=C, Q$. These conditions are satisfied in models (a) and (b) of Lemma 9.

When firms are myopic, we can further extend the model to allow for stochastic investment returns, as in Athey and Schmutzler (1995). For example, suppose that (i) (9) holds for each type of investment, (ii) the returns to demand-enhancing innovation are distributed independently of the returns to cost-reducing innovation, ${ }^{30}$ and (iii) investments in costreduction do not affect the distribution of quality improvements (and vice versa). Then, leading firms will invest more in both cost-reducing and demand-enhancing innovation.

\subsection{Patent race models}

In this section, we apply our framework to models of patent races. Although our results are ambiguous, they can be used to organize the competing effects that arise in the existing literature (Reinganum 1985, Vickers 1986, Beath et al. 1987). Suppose $a_{i}^{t}$ is R\&D investment. As in the case of incremental investment, $Y_{i}^{t}$ is the cumulated cost reduction from some common reference level $\bar{c}$ or the quality level. However, we modify our assumptions about the investment technology. In each period the firms invest in R\&D in an attempt to attain a patent. If firm $i$ receives the patent, it will achieve an exogenously fixed level of the state variable, where that level is an improvement over the best present state: $Y_{i}^{t}=\bar{Y}^{t}>$ $\max _{k \in\{1, \ldots, I\}} Y_{k}^{t-1} .^{31}$ In each period, one firm will receive the patent; for the other firms, the states remain the same $\left(Y_{i}^{t}=Y_{i}^{t-1}\right)$. The probability that firm $i$ obtains a patent is $P^{i}\left(a^{t}\right)$, where $\partial P^{i} / \partial a_{i}^{t}>0$ and $\partial P^{i} / \partial a_{k}^{t}<0$ for $k \neq i .^{32}$

Denoting the $k$-th unit vector as $\mathbf{e}_{k}$, firm $i$ 's expected product market profit is written:

$$
E \pi^{i}\left(\mathbf{a}^{t}, \mathbf{Y}^{t-1}\right)=\sum_{k=1}^{I}\left[\hat{\pi}^{i}\left(\mathbf{Y}^{t-1}+\mathbf{e}_{k}\left(\bar{Y}^{t}-Y_{k}^{t-1}\right)\right)\right] P^{k}\left(\mathbf{a}^{t}\right)
$$

\footnotetext{
${ }^{30}$ More generally, if the investments are correlated, the investments must satisfy a condition found in Athey and Schmutzler (1995).

${ }^{31}$ As in many of the patent race papers, we therefore assume that the level of the state that can be achieved as a result of a patent is given exogenously in each period.

${ }^{32}$ It is possible to map these assumptions into conditions on the joint distribution function $H\left(\mathbf{y}^{t} \mid \mathbf{a}^{t}, \mathbf{Y}^{t-1}\right)$, but the notation in terms of $P$ is more intuitive for this problem. More generally, we might also consider races where more than one firm can obtain a patent and the size of the prize may not be fixed (because firms can pursue different R\&D-projects).
} 
Finally, assume that previous investment success has no effect on marginal R\&D costs $\left(\frac{\partial^{2}}{\partial a_{i}^{t} \partial Y_{i}^{t-1}} k^{i}=0\right)$. Of course, if we assume instead (in the spirit of Rogerson (1982)) that leaders have a lower marginal cost of $\mathrm{R} \& \mathrm{D}$, the case for weak increasing dominance would be strengthened.

If there are only two firms, then

$$
\left(E \pi^{i}\right)_{a_{i}, Y_{j}}=\sum_{k \neq j}\left[\widehat{\pi}_{Y_{j}}^{i}\left(\mathbf{Y}^{t-1}+\mathbf{e}_{k}\left(\bar{Y}^{t}-Y_{k}^{t-1}\right)\right)\right] \frac{\partial}{\partial a_{i}^{t}} P^{k}\left(\mathbf{a}^{t}\right) \leq 0,
$$

as required by (WID-P). ${ }^{33}$ Intuitively, the lower the level of the opponent's state variable, the larger is the incremental effect of a patent, and thus the greater the profit increase to the firm from taking the patent away from the opponent. Next, consider whether firm investments are strategic substitutes. Suppose that profits are close to zero if the firm does not attain a patent. Then, $\left(E \pi^{i}\right)_{a_{i}, a_{j}} \leq 0$ if $\frac{\partial^{2}}{\partial a_{i}^{t} \partial a_{j}^{t}} P^{i}\left(\mathbf{a}^{t}\right)$ is sufficiently negative. In words, the probability that firm $i$ attains a patent is less sensitive to firm $i$ 's investment when firm $j$ invests more. However, even under this assumption, (WID-P) fails in general, since firms with higher current states will see lower returns to investing:

$$
\left(E \pi^{i}\right)_{a_{i}, Y_{i}}=\sum_{k \neq i}\left[\widehat{\pi}_{Y_{i}}^{i}\left(\mathbf{Y}^{t-1}+\mathbf{e}_{k}\left(\bar{Y}^{t}-Y_{k}^{t-1}\right)\right)\right] \frac{\partial}{\partial a_{i}^{t}} P^{k}\left(\mathbf{a}^{t}\right) \leq 0 .
$$

The intuition is simple: the better a firm already is, the smaller the increase of the state that it receives as a consequence of a successful patent, and hence the smaller the resulting profit increase.

In conclusion, we cannot make an unambiguous case for either increasing or decreasing dominance, since the own-state effect works against the opponent-state effect. However, it can be shown that increasing dominance still holds if the negative effect of a competitor's higher state on investment incentives is substantial relative to the negative effect of a firm's own state on investment incentives. To see this, suppose that increasing dominance is violated. Without loss of generality, suppose that the violation concerns firms 1 and 2. Then, there must exist $Y_{H}>Y_{L}$ and $a_{H}>a_{L}$ such that in equilibrium, $Y_{1}=Y_{H}, Y_{2}=Y_{L}, a_{1}=a_{L}$, and $a_{2}=a_{H}$. Suppose that adjustment costs are sufficiently convex in actions such that each

\footnotetext{
${ }^{33}$ In the case of $I>2$ firms, it is even possible that $\frac{\partial^{2}\left(E \pi_{i}\right)}{\partial a_{i}^{t} Y_{j}^{t-1}}>0$, since for $k \neq i, j$, $\frac{\partial \pi_{i}}{\partial Y_{j}^{t-1}}\left(Y^{t-1}+\mathbf{e}_{k}\left(\bar{Y}^{t}-Y_{k}^{t-1}\right)\right) \frac{\partial P_{k}\left(a^{t}\right)}{\partial a_{i}^{t}}$ is positive.
} 
firm's objective function is globally concave in the investment, and investment choices are interior. Hold fixed the actions and states of firms 3 and higher at $a_{-12}^{*}(Y)$, and suppress these in the notation. Then, the first-order conditions for players 1 and 2 and exchangeability imply that

$$
\Pi_{a_{1}}^{1}\left(a_{L}, a_{H} ; Y_{H}, Y_{L}\right)=\Pi_{a_{1}}^{1}\left(a_{H}, a_{L} ; Y_{L}, Y_{H}\right)=0
$$

By concavity, $\Pi_{a_{1}}^{1}\left(a_{L}, a_{L} ; Y_{L}, Y_{H}\right)>0$. Hence,

$$
\Pi_{a_{1}}^{1}\left(a_{L}, a_{L} ; Y_{L}, Y_{H}\right)-\Pi_{a_{1}}^{1}\left(a_{L}, a_{H} ; Y_{H}, Y_{L}\right)>0
$$

But,

$$
\begin{aligned}
\Pi_{a_{1}}^{1}\left(a_{L}, a_{L} ; Y_{L}, Y_{H}\right)- & \Pi_{a_{1}}^{1}\left(a_{L}, a_{H} ; Y_{H}, Y_{L}\right)=\Pi_{a_{1}}^{1}\left(a_{L}, a_{L} ; Y_{L}, Y_{H}\right)-\Pi_{a_{1}}^{1}\left(a_{L}, a_{H} ; Y_{L}, Y_{H}\right) \\
& +\Pi_{a_{1}}^{1}\left(a_{L}, a_{H} ; Y_{L}, Y_{H}\right)-\Pi_{a_{1}}^{1}\left(a_{L}, a_{H} ; Y_{H}, Y_{H}\right) \\
& +\Pi_{a_{1}}^{1}\left(a_{L}, a_{H} ; Y_{H}, Y_{H}\right)-\Pi_{a_{1}}^{1}\left(a_{L}, a_{H} ; Y_{H}, Y_{L}\right) \\
< & \left(a_{H}-a_{L}\right)\left(-\inf _{\mathbf{a}, \mathbf{Y}} \Pi_{a_{1}, a_{2}}^{1}\right)+\left(Y_{H}-Y_{L}\right)\left(-\inf _{\mathbf{a}, \mathbf{Y}} \Pi_{a_{1}, Y_{1}}^{1}+\sup _{\mathbf{a}, \mathbf{Y}} \Pi_{a_{1}, Y_{2}}^{1}\right)
\end{aligned}
$$

Then, if $\Pi_{a_{1}, a_{2}}^{1}$ is not too negative, adjustment costs are sufficiently high such that $\left(a_{H}-\right.$ $\left.a_{L}\right)$ is not too large relative to $\left(Y_{H}-Y_{L}\right)$, and $\sup _{\mathbf{a}, \mathbf{Y}} \Pi_{a_{1} Y_{2}}^{1}<\inf _{\mathbf{a}, \mathbf{Y}} \Pi_{a_{1} Y_{1}}^{1},(10)$ fails and weak increasing dominance holds. In words, weak increasing dominance follows if the investments are not strong strategic substitutes, and the decrease in the marginal return to investment from a higher level of a firm's own state is small relative to the increase in the marginal return to investment from a higher level of opponent states. $^{34}$

Note, however, that even if weak increasing dominance holds, leapfrogging is possible. By sheer luck, a laggard might overtake the leader even though he invests less. If this happens, he will have higher investment incentives once he takes the lead.

\subsubsection{A Potential Extension: Incremental versus Radical Innovation}

Now consider whether weak increasing dominance can be expected in a model where firms can choose to invest in both incremental improvements and more radical innovation. For

\footnotetext{
${ }^{34}$ Existing literature on patent races has taken notice of the fact that product market competition might matter for whether or not increasing dominance arises. For instance, in Vickers (1986), weak increasing dominance arises for Bertrand competition, but not for Cournot competition. However, the conditions identified here have to our knowledge not been derived elsewhere.
} 
example, suppose that the state variable for each firm is one-dimensional (i.e. the current level of cost reduction), but that firms can choose two action variables, denoted $\left(a_{i C}, a_{i P}\right)$, where $a_{i C}$ as an incremental investment, and of $a_{i P}$ as a radical investment which can potentially lead to a major jump in the state variable. These action variables both increase the state variable: $y_{i}=y_{i}\left(a_{i C}, a_{i P}\right)$ with $\partial y_{i} / \partial a_{i C}>0$ and $\partial y_{i} / \partial a_{i P}>0 .{ }^{35}$ Further, assume that these variables are substitutes in improving the state: $\partial^{2} y_{i} / \partial a_{i C} \partial a_{i P}<0$, as would be true if implementing the radical investment makes incremental cost improvements obsolete. ${ }^{36}$ Assuming that investments take place before competition, product market profits are therefore given by $\widehat{\pi}^{i}\left(\mathbf{Y}+\mathbf{y}\left(a_{C}, a_{P}\right)\right)$.

In the one-dimensional case we saw that weak increasing dominance is likely for incremental investments if WID-O holds for $\widehat{\pi}^{i}$, but less likely for radical investments. Thus, a natural conjecture is that leading firms invest more in incremental investment, while lagging firms invest more in radical innovation. While this behavior might obtain, it need not in general. To see this, observe that deriving such a result from Theorem 5 would require the following conditions.

$$
\begin{aligned}
(a) \Pi_{a_{i C}, a_{i P}}^{i} & \leq 0 ;(b) \Pi_{a_{i C}, a_{j C}}^{i} \leq 0 \text { and } \Pi_{a_{i C}, a_{j P}}^{i} \geq 0 \\
(c) \Pi_{a_{i C}, Y_{i}}^{i} & \geq 0 \text { and } \Pi_{a_{i P}, Y_{i}}^{i} \leq 0 ;(d) \Pi_{a_{i C}, Y_{j}}^{i} \geq 0 \text { and } \Pi_{a_{i P}, Y_{j}}^{i} \leq 0
\end{aligned}
$$

The second condition in (b) will fail in general. To see why, observe that by the definition of $y_{i}\left(a_{i C}, a_{i P}\right), a_{i C}$ increases $y_{i}$, and $a_{j P}$ increases $y_{j}$, but $\Pi_{Y_{i}, Y_{j}}^{i} \leq 0$ if WID-O holds. Thus, all opponent actions interact with a firm's own actions in qualitatively similar ways. Intuitively, if investment precedes product market competition, then all opponent investments interact with own investments in the same way. Thus, an increase in firm $j$ 's investment in incremental innovation decreases the returns to both incremental and radical innovation for firm $j \cdot{ }^{37}$

\footnotetext{
${ }^{35}$ More generally, we could consider combining the model of incremental investment with a patent race model, as described above.

${ }^{36}$ We ignore complications arising because of stochastic R\&D here.

${ }^{37}$ In a related paper, Cabral (1999) analyzes a model where firms can choose between two different types of innovative investments. In this model, if the firms make identical choices about investment, the outcomes are perfectly correlated, while otherwise they are independent. In this setting, it turns out that leaders want to imitate laggards, whereas laggards want to differentiate themselves from leaders.
} 


\subsection{Learning-by-doing}

In learning-by-doing models (e.g. Cabral and Riordan (1994), Sutton (1998, ch. 14)), costs are monotone decreasing functions of previous output levels. It is well understood that this force works towards increasing dominance, although countervailing effects arise once leading firms have exhausted most of the opportunities for learning. In the following, we shall apply our approach to show how the nature of product market competition influences which force dominates. ${ }^{38}$

Denote the output level as $a_{i}^{t}$. $Y_{i}^{t}$ is the cumulated cost reduction from some common reference level $\bar{c}$. Hence, we write

$$
Y_{i}^{t}=r\left(\sum_{\tau=1}^{t} a_{i}^{\tau}\right)
$$

where $r$ is a strictly increasing and concave function. In this case, if investment returns are deterministic, we let $\check{\pi}^{i}\left(\mathbf{a}^{t}, \mathbf{Y}^{t-1}\right)$ represent the product market profit of a firm $i$ when its cumulated cost reduction is given by $Y_{i}^{t-1}$ and the output level by $a_{i}^{t}$. Further, the state variable develops according to

$$
Y_{i}^{t}=r\left(r^{-1}\left(Y_{i}^{t-1}\right)+a_{i}^{t}\right)
$$

Hence,

$$
y_{i}^{t}=y_{i}^{t}\left(Y_{i}^{t-1}, a_{i}^{t}\right)=r\left(r^{-1}\left(Y_{i}^{t-1}\right)+a_{i}^{t}\right)-Y_{i}^{t-1}
$$

satisfies $\partial^{2} y_{i}^{t} / \partial a_{i}^{t}>0$ and $\partial^{2} y_{i}^{t} / \partial Y_{i}^{t-1} \partial a_{i}^{t}<0$. Finally, we set $k^{i} \equiv 0$, as all costs and benefits of increasing output are borne through the product market profit.

Consider the example of Cournot competition with inverse market demand function $p(\cdot)$, so that $\Pi^{i}(\mathbf{Y}, \mathbf{a})=\left[p\left(\sum_{k=1}^{I} a_{k}\right)-\bar{c}+Y_{i}\right] a_{i}$. We now argue that (WID-O) holds for this model. First, it is standard to assume that $\Pi_{a_{i}, a_{j}}^{i}<0$ in a Cournot model, in order to guarantee existence of equilibrium (see Novshek 1985). Further, $\Pi_{a_{i}, Y_{i}}^{i}=1>0$, due to scale effects: an increase in output is more valuable for a low cost firm. Finally, $\Pi_{a_{i}, Y_{j}}^{i}=0$. Hence,

\footnotetext{
${ }^{38} \mathrm{It}$ is simple to reinterpret the following as a model of network or standardization effects along the lines of Farrell and Saloner (1986), Katz and Shapiro (1986), where firms that manage to acquire many customers in an early phase of the market benefit if customers' willingness to pay grows with the number of other customers adhering to the same standard or using the same network. Here $Y_{i}^{t}$ is a measure of perceived quality rather than total cost reduction.
} 
when firms are myopic, leading firms will always have stronger incentives to increase output and thus increase their state variable. That is, weak increasing dominance holds without additional assumptions, provided the Cournot game has a unique equilibrium.

For forward-looking firms, however, the nature of product market competition plays a decisive role in determining whether increasing dominance arises. For simplicity, consider a two-period framework. The long-run profit of firm $i$ can be written as

$$
L R^{i}\left(\mathbf{Y}^{0}, \mathbf{a}^{1}\right)=\check{\pi}^{i}\left(\mathbf{a}^{1}, \mathbf{Y}^{0}\right)+\tilde{\pi}^{i}\left(Y_{i}^{0}+y_{i}^{1}\left(Y_{i}^{0}, a_{i}^{1}\right), \mathbf{Y}_{-i}^{0}+y_{-i}^{1}\left(\mathbf{Y}_{-i}^{0}, \mathbf{a}_{-i}^{1}\right)\right)
$$

where $\tilde{\pi}^{i}\left(\mathbf{Y}^{1}\right)$ is the Cournot profit for cost structure $\left(\mathbf{Y}^{1}\right)$. Applying Theorem 5, weak increasing dominance will obtain if the following conditions hold for all $i \neq j$ :

$$
\begin{gathered}
\frac{\partial^{2} L R^{i}}{\partial a_{i}^{1} \partial Y_{i}^{0}}=\frac{\partial^{2} \check{\pi}^{i}}{\partial a_{i}^{1} \partial Y_{i}^{0}}+\frac{\partial^{2} \widetilde{\pi}^{i}}{\left(\partial Y_{i}^{1}\right)^{2}}\left(\frac{\partial y_{i}^{1}}{\partial Y_{i}^{0}}+1\right) \frac{\partial y_{i}^{1}}{\partial a_{i}^{1}}+\frac{\partial^{2} y_{i}^{1}}{\partial a_{i}^{1} \partial Y_{i}^{0}} \frac{\partial \widetilde{\pi}^{i}}{\partial y_{i}^{1}} \geq 0 \\
\frac{\partial^{2} L R^{i}}{\partial a_{i}^{1} \partial Y_{j}^{0}}=\frac{\partial^{2} \check{\pi}^{i}}{\partial a_{i}^{1} \partial Y_{j}^{0}}+\frac{\partial^{2} \widetilde{\pi}^{i}}{\partial Y_{i}^{1} \partial Y_{j}^{1}} \frac{\partial y_{i}^{1}}{\partial a_{i}^{1}}\left(1+\frac{\partial y_{j}^{1}}{\partial Y_{j}^{0}}\right) \leq 0 ; \\
\frac{\partial^{2} L R^{i}}{\partial a_{i}^{1} \partial a_{j}^{1}}=\frac{\partial^{2} \check{\pi}^{i}}{\partial a_{i}^{1} \partial a_{j}^{1}}+\frac{\partial^{2} \widetilde{\pi}^{i}}{\partial Y_{i}^{1} \partial Y_{j}^{1}} \frac{\partial y_{j}^{1}}{\partial a_{j}^{1}} \frac{\partial y_{i}^{1}}{\partial a_{i}^{1}} \leq 0 .
\end{gathered}
$$

We have already shown that the mixed derivatives of $\check{\pi}^{i}$ have the correct sign under very general conditions. As to the remaining terms, there are two countervailing effects. As long as $\widetilde{\pi}^{i}$ satisfies condition (WID-O), the signs of the second derivatives of $\widetilde{\pi}^{i}$ are correct. However, $\frac{\partial^{2}}{\partial a_{i}^{1} \partial Y_{i}^{0}} y_{i}^{1}$ is negative, reflecting the slow-down in learning for a better firm. This competing effect works against the product market effect in the first expression. For weak increasing dominance to arise with forward-looking firms, it is therefore important that the product market effects dominate.

Of course, most applications will combine some elements of learning-by-doing, incremental investment, and investments in more radical innovations similar to the patent-race models. For example, it has been widely asserted that in the market for memory chips, learning-by-doing effects play an important role. However, increasing dominance only arises in some parts of this market. For example, the market for DRAM chips does not exhibit increasing dominance (Gruber, 1994). Within each product generation $(4 \mathrm{~K}, 16 \mathrm{~K}, 64 \mathrm{~K}, 256 \mathrm{~K}$, 
$1 \mathrm{MB}$ chips), concentration levels did not increase (at least, not substantially); and across each product generation, leadership patterns often changed. The latter finding is not surprising, given that across generations, learning-by doing effects are much less significant. Dynamic competition across generations is more akin to patent competition, where laggards potentially have higher investment incentives. In contrast, the EPROM market shows stable leadership patterns, even across product generations; Gruber (1994) argues that learning-by doing effects tend not to be exhausted within one product generation in this market.

\subsection{Strategic Trade Policy}

Our model can also be applied to analyze strategic trade policy. One set of questions concerns the consequences of R\&D subsidies by governments (Spencer and Brander, 1983). In a setting with one home firm and one foreign firm, a government that subsidizes R\&D, thereby increasing its own firm's innovation incentives, will at the same time reduce the foreign firm's innovation incentives, to the advantage of the home country, since R\&D investments are typically strategic substitutes (Bagwell and Staiger, 1994). Such an argument can be used to support temporary R\&D subsidies, subsidies that are presumably desirable only if they lead to lasting increases in the home firm's market share. However, following the logic of this paper, if increasing dominance plays a role, temporary subsidies may not serve the long-term goal unless the home firm actually surpasses the foreign firm.

More generally, we can use the results in this paper to formally analyze the dynamic evolution of other trade policies, such as export subsidies, even in the absence of innovation. Rather than apply our framework to product market competition between the firms, we instead analyze the game between the governments of two countries, where the governments choose to subsidize their export industries (and these choices might evolve over time). For simplicity we consider the simple case (first analyzed by Brander and Spencer (1985)) where the firms, after receiving their subsidies, play a Cournot game; more generally, we might incorporate learning-by-doing. Our goal is to use Theorem 5 to analyze conditions under which a leading country sees a greater return to using subsidies than a lagging country. In that case, lagging countries may be better off if export subsidies are prohibited.

Formally, suppose two firms from countries $i=1,2$ serve a third country's market. Firms are Cournot competitors, and demand is linear: $q=\alpha-p$. Each firm chooses output levels 
$q_{i}$ so as to maximize firm profits plus $z_{i} q_{i}$, where $z_{i}$ is the per-unit export subsidy chosen by country $i$. Countries choose subsidies so as to maximize their firm's profits in the ensuing oligopoly game. Simple derivations (see, for example, Fershtman and Judd (1987, p. 930)) show that, when each firm $i$ 's constant marginal cost is denoted $c_{i}$,

$$
\Pi^{i}\left(z_{i}, z_{j}\right)=\frac{\left(\alpha+c_{i} /\left(1+z_{i}\right)+c_{j} /\left(1+z_{j}\right)-3 c_{i}\right)\left(\alpha-2 c_{i} /\left(1+z_{i}\right)+c_{j} /\left(1+z_{j}\right)\right)}{9 b} .
$$

Hence, subsidies are strategic substitutes, and the incentive to subsidize is higher when the opponent's cost is higher:

$$
\Pi_{z_{i}, z_{j}}^{i}=\frac{-c_{i} c_{j}}{\left(1+z_{i}\right)^{2}\left(1+z_{j}\right)^{2}}<0 \text { and } \Pi_{z_{i}, c_{j}}^{i}=\frac{c_{i}}{\left(1+z_{i}\right)^{2}\left(1+z_{j}\right)}>0 .
$$

However, the incentive to subsidize may not be monotonic in the home firm's cost:

$$
\Pi_{z_{i}, c_{i}}^{i}=\frac{\alpha}{\left(1+z_{i}\right)^{2}}+\frac{8 c_{i}}{\left(1+z_{i}\right)^{3}}+\frac{c_{j}}{\left(1+z_{j}\right)\left(1+z_{i}\right)^{2}}-\frac{12 c_{i}}{\left(1+z_{i}\right)^{2}} .
$$

The sign of the last expression depends on parameter values. For approximately identical subsidies, the sign is negative if and only if $\left(\alpha-12 c_{i}\right)(1+z)+c_{j}+8 c_{i}<0$, which holds if costs do not differ too much from each other and from $\alpha$. Applying the logic of Theorem 5 leads us to conclude that when countries are not very different, the leading country has a larger incentive to subsidize exports, undermining the standard infant industry protection argument. One would therefore expect a leading country to expand its lead in the early stages of such a strategic subsidy game. When firms are very different, however, Theorem 5 cannot be applied; either leading or lagging countries might have higher investment incentives, depending on the parameters. For example, if the cost of the leading firm is very low, it will have little incentive to subsidize.

\section{Conclusions}

This paper analyzes oligopolistic firms that can engage in demand-enhancing or cost-reducing activities, providing conditions under which a firm is likely to increase an initial advantage over competitors. The main forces that might lead to such a development are scale effects resulting from product market competition. Whether there are strong countervailing effects depends on the nature of the investment process. When "investment" is just a by-product of 
large output, such as in learning-by-doing or network models, the product-market effects are reinforced by the investment process. When firms can improve their states via incremental investment, countervailing forces arise if lagging firms find it somewhat less costly than leading firms to improve their states. When investment is of the patent race type, there is a systematic effect working against increasing dominance, which will often dominate the product market effect. Finally, competing effects can arise when firms are sufficiently farsighted.

More generally, our result about games with strategic substitutes represent a contribution to the literature that uses lattice-theoretic tools to analyze strategic behavior. The result could be applied to a variety of other games with strategic substitutes. In the present context, we have argued that most of the commonly studied oligopoly models have forces that favor strategic substitutability. Thus, our approach, which does not rely on specific functional form assumptions, can be used to extend the existing literature. For example, it is commonly assumed in $I$-player oligopoly games that one firm cares only about the sum of opponent choices. This restriction is imposed in order to effectively reduce an $I$-player game to a two-player game. In this paper, we have shown that a much more general assumption suffices. Namely, we require exchangeability of the firm profit functions. We show that this assumption is sufficient to generate many interesting empirical predictions and comparative statics results. However, our approach still has limitations in dynamic games, unless the firms commit in advance to investment plans and do not adjust them in response to changes in opponent investments.

We expect that the techniques developed in this paper can be fruitfully applied in a variety of other problems in industrial organization. Section 4.4 is suggestive of applications to delegation games. In an example of an application outside of the oligopoly context, the players could be workers in a firm engaged in repeated tournaments for promotions, where human capital investments are possible in each period. The methods of this paper could be applied to understand under which circumstances (e.g. promotion policies) workers who get ahead of others in early periods of the game are likely to increase their lead.

In conclusion, we observe that our results provide a lens through which to analyze several public policy questions. In particular, several anti-trust policies that might serve to limit increasing concentration, such as prohibitions against predatory pricing and mergers, can 
have ambiguous welfare effects. Even if it can be established that a particular policy works for or against increasing dominance, often the investment required for a firm to achieve market dominance are beneficial to consumers.

Consider first the case of mergers. Even if an industry is characterized by increasing dominance, some symmetry-increasing mergers (such as mergers among lagging firms) may slow the evolution of market dominance. However, even mergers among leading firms have some welfare benefits: for example, in an incremental investment game, increases in market share are the direct result of larger improvements in cost or quality.

Similar logic applies to predatory pricing. Broadly speaking, predatory pricing occurs when firms set low prices in order to induce market exit, reduce a competitor's output, or prevent entry. The rule of Areeda-Turner (1975) considers any prices below marginal costs as predatory. In contrast, Baumol (1979) proposes a rule whereby a firm that increases its price after the exit of a competitor is guilty of predatory pricing. Our approach is consistent with a view suggested elsewhere (Bagwell et al. 1997, Cabral and Riordan 1994): the Baumol condition may be satisfied, even when welfare is not harmed. In an incremental investment game, a firm drives out its competitor by sufficiently lowering its cost. Even if the leading firm raises prices after a competitor exits, the price might end up lower than when the firms were fairly similar in size.

\section{Appendix}

Proof of Lemma 9: For parts (a)-(c), the argument relies on the decomposition of profits outlined in Section 3.3. In all the cases under consideration, demand and markups are linear functions of the state variables. Hence the desired properties follow.

(a) Consider a duopoly with inverse demand functions

$$
p_{1}=\alpha_{1}-\beta q_{1}-\gamma q_{2} ; p_{2}=\alpha_{2}-\gamma q_{1}-\beta q_{2}
$$

for output levels $q_{1}$ and $q_{2}$ and parameters $\beta>\gamma>0 ; a_{1}, a_{2}>0$.

For the case of price competition, straightforward calculations show that

$$
m_{i}=\frac{\left(2 \beta^{2}-\gamma^{2}\right)\left(\alpha_{i}-c_{i}\right)-\beta \gamma\left(\alpha_{j}-c_{j}\right)}{4 \beta^{2}-\gamma^{2}} ; D_{i}=\frac{\left(2 \beta^{3}-\gamma^{2}\right)\left(\alpha_{i}-c_{i}\right)-\beta^{2} \gamma\left(\alpha_{j}-c_{j}\right)}{\left(4 \beta^{2}-\gamma^{2}\right)\left(\beta^{2}-\gamma^{2}\right)} .
$$

Clearly, these expressions are linear in marginal costs, increasing in $c_{i}$ and decreasing in $c_{j}$, so that Lemma 8 can be applied for cumulated cost reduction as the state variable. The same argu- 
ment works for the quality parameters $\alpha_{i}, \alpha_{j}$, and the difference between quality and cost. Hence, conditions (WID-O) and (WID-O') (the latter condition defined in Section 4.1.1) hold.

For the case of quantity competition, the argument is the same, using

$$
D_{i}=\frac{2 \beta\left(\alpha_{i}-c_{i}\right)-\gamma\left(\alpha_{j}-c_{j}\right)}{4 \beta^{2}-\gamma^{2}} ; m_{i}=\frac{2 \beta^{2}\left(\alpha_{i}-c_{i}\right)-\beta \gamma\left(\alpha_{j}-c_{j}\right)}{4 \beta^{2}-\gamma^{2}}
$$

(b) Consider the standard Hotelling model of competition on the line, with firms located at $w_{i} \in[0,1]$ producing a good for which consumers have willingness to pay $v_{i}$. Suppose customers are distributed uniformly on the unit interval. Suppose transportation costs for customer $w$ are $t\left(w-w_{i}\right)^{2}$. Then, assuming that in equilibrium both firms have unit demand and the entire interval is covered, it turns out that the markup and demand can be written as

$$
D_{i}=\frac{\left(v_{i}-c_{i}-v_{j}+c_{j}\right)}{6 t\left|w_{j}-w_{i}\right|} ; m_{i}=\frac{\left(v_{i}-c_{i}-v_{j}+c_{j}\right)}{3} .
$$

Hence, no matter whether $c_{i}, v_{i}$ or $v_{i}-c_{i}$ is used as a state variable, the equilibrium markup and demand are both linear functions of these state variables.

Similar reasoning shows that when firms are located on a circle, demand and mark-up are linear functions of marginal costs (see Eswaran and Gallini 1996 for details).

(c),(d) In this model, ${ }^{39}$ firms sell products of different qualities $v_{i}$. Customers differ in their valuation $\sigma$ for quality. This taste parameter is distributed uniformly across the interval $[\underline{\sigma}, \bar{\sigma}]$, where $\bar{\sigma} \geq 2 \underline{\sigma}$. In this case, it is straightforward to show that the conditions of Lemma 8 still hold for $Y_{i}=\bar{c}-c_{i}$ where $\bar{c}$ is some reference cost level. Now consider $Y_{i}=v_{i}$, in the boundary case that costs are identical. Profits can be written as

$$
\widehat{\pi}^{i}=\left\{\begin{array}{l}
\frac{1}{9}\left(v_{j}-v_{i}\right)[\bar{\sigma}-2 \underline{\sigma}]^{2} \text { for } v_{i}<v_{j} \\
\frac{1}{9}\left(v_{i}-v_{j}\right)[2 \bar{\sigma}-\underline{\sigma}]^{2} \text { for } v_{i} \geq v_{j}
\end{array}\right\} .
$$

Thus $\pi_{Y_{i}, Y_{j}}^{i}=0$, wherever this is defined. It suffices to show that for $Y_{i} \geq Y_{j}$, any incremental investment $d y$ increases profits more for firm $i$ than for firm $j$. This follows because the value of such an investment is $[2 \bar{\sigma}-\underline{\sigma}]^{2} d y$ for firm $i$, whereas for firm $j$ it is

$$
\max \left[(\bar{\sigma}-2 \underline{\sigma})^{2} d y,\left(d y-Y_{i}+Y_{j}\right)(2 \bar{\sigma}-\underline{\sigma})^{2}-\left(Y_{i}-Y_{j}\right)(\bar{\sigma}-2 \underline{\sigma})^{2}\right] .
$$

Proof of Proposition 11: Let $\vec{a}_{i}^{*}=\left(a_{i}^{1}, \ldots, a_{i}^{T}\right) ; \vec{a}_{j}=\left(a_{j}^{1}, \ldots, a_{j}^{T}\right)$ and $\overrightarrow{\mathbf{a}}=\left(\vec{a}_{i}, \vec{a}_{j}\right)$. Clearly, if we can show that $Y_{r}^{0}>Y_{s}^{0}$ implies $\vec{a}_{r} \geq \vec{a}_{s}$, the result follows. To apply Theorem 5 , it suffices to show that (OSPM) holds, and the game has strategic substitutes and increasing differences in $\left(a_{i}^{t}, Y_{i}^{0}\right)$

${ }^{39}$ To be precise, the following is a slightly modified version of the original Shaked and Sutton model (Tirole 1989, ch. 7.5.1). 
and in $\left(a_{i}^{t},-Y_{j}^{0}\right)$. To see that these conditions hold, note that the long-run profit function of firm $i$ can be written as

$$
\begin{aligned}
L R^{i}\left(\mathbf{a}, \mathbf{Y}^{0}\right)= & \Pi^{i}\left(\mathbf{a}^{1}, \mathbf{Y}^{0}\right)+\delta \Pi^{i}\left(\mathbf{a}^{2}, \mathbf{Y}^{0}+\mathbf{a}^{1}\right)+\ldots \\
& +\delta^{t-1} \Pi^{i}\left(\mathbf{a}^{t}, \mathbf{Y}^{0}+\mathbf{a}^{1}+\ldots+\mathbf{a}^{t-1}\right)+\ldots
\end{aligned}
$$

(OSPM) requires: ${ }^{40}$

$$
\frac{\partial^{2} L R^{i}}{\partial a_{i}^{t} \partial a_{i}^{s}}=\delta^{t-1} \Pi_{a_{i}, Y_{i}}^{i}+\delta^{t} \Pi_{Y_{i}, Y_{j}}^{i}+\ldots+\delta^{T-1} \Pi_{Y_{i}, Y_{j}} \geq 0 \text { for } s<t .
$$

To guarantee strategic substitutes, we require:

$$
\begin{aligned}
\frac{\partial^{2} L R^{i}}{\partial a_{i}^{t} \partial a_{j}^{t}} & =\delta^{t-1} \Pi_{a_{i}, a_{j}}^{i}+\delta^{t} \Pi_{Y_{i}, Y_{j}}^{i}+\ldots+\delta^{T-1} \Pi_{Y_{i}, Y_{j}}^{i} \leq 0 \text { for } t \in\{1, \ldots, T\} . \\
\frac{\partial^{2} L R^{i}}{\partial a_{i}^{t} \partial a_{j}^{s}} & =\delta^{s-1} \Pi_{a_{j}, Y_{i}}^{i}+\delta^{s} \Pi_{Y_{i}, Y_{j}}^{i}+\ldots+\delta^{T-1} \Pi_{Y_{i}, Y_{j}}^{i} \leq 0 \text { for } t \in\{1, \ldots, T\} \text { and } s>t . \\
\frac{\partial^{2} L R^{i}}{\partial a_{i}^{t} \partial a_{j}^{s}} & =\delta^{t-1} \Pi_{a_{i}, Y_{j}}^{i}+\delta^{t} \Pi_{Y_{i}, Y_{j}}^{i}+\ldots+\delta^{T-1} \Pi_{Y_{i}, Y_{j}}^{i} \leq 0 \text { for } t \in\{1, \ldots, T\} \text { and } s<t .
\end{aligned}
$$

The increasing differences conditions require the following:

$$
\begin{aligned}
\frac{\partial^{2} L R^{i}}{\partial a_{i}^{t} \partial Y_{i}^{o}} & =\delta^{t-1} \Pi_{a_{i}, Y_{j}}^{i}+\delta^{t} \Pi_{Y_{i}, Y_{j}}^{i}+\ldots+\delta^{T-1} \Pi_{Y_{i}, Y_{j}}^{i} \geq 0 \text { for } t \in\{1, \ldots, T\} \\
\frac{\partial^{2} L R^{i}}{\partial a_{i}^{t} \partial Y_{j}^{o}} & =\delta^{t-1} \Pi_{a_{i}, Y_{j}}^{i}+\delta^{t} \Pi_{Y_{i}, Y_{j}}^{i}+\ldots+\delta^{T-1} \Pi_{Y_{i}, Y_{j}}^{i} \leq 0 \text { for } t \in\{1, \ldots, T\}
\end{aligned}
$$

All of these conditions are clearly implied by (WID) and (WID-D1).

Proof of Proposition 12: Let $V^{i, t}\left(\mathbf{Y}^{t}\right)$ be the value of the firm in period $t$, and let $\mathbf{a}^{t}\left(\mathbf{Y}^{t}\right)$ be the equilibrium policy vector in period $t$.

Step 1: Show that condition (1) in the Proposition implies (2), i.e., the assumptions of Lemma 8 imply linear (and thus differentiable) policy functions in each period, (WID-A) and (WID-D2). Let

$$
T^{i}(\mathbf{V})=\Pi^{i}\left(\mathbf{a}^{X}, \mathbf{Y}\right)+\delta V^{i}\left(\mathbf{a}^{X}+\mathbf{Y}\right)
$$

where $\mathbf{a}^{X}$ is the Nash equilibrium of the auxiliary static game where player $i$ 's payoffs are given by $\Pi^{i}(\mathbf{a}, \mathbf{Y})+\delta V^{i}(\mathbf{a}+\mathbf{Y})$. Then if $\Pi^{i}$ is quadratic, $T^{i}(\mathbf{V})$ maps quadratic functions into quadratic functions, as the equilibrium strategies $\mathbf{a}^{X}$ will be linear. Since $V^{i, T-1}\left(\mathbf{Y}^{T-1}\right)$ is quadratic, the value function in each period will therefore be quadratic, and the policy functions linear and continuously differentiable. (WID-A) and (WID-D2) therefore hold.

\footnotetext{
${ }^{40}$ Here and in the following, mixed partials differ according to where they are evaluated; as this does not affect our results, we drop the arguments.
} 
Step 2: Show that condition (2) of the Proposition implies that the value function is continuously differentiable for each $t$.

Since each firm has a unique best response, actions are chosen from a compact set, $a_{j}^{t}\left(\mathbf{Y}^{t-1}\right)$ is continuously differentiable in $Y_{i}^{t-1}$, and $\Pi^{i}$ is twice continuously differentiable, the envelope theorem implies that if $V^{i, t}$ is continuously differentiable, then

$$
V^{i, t-1}\left(\mathbf{Y}^{t-1}\right)=\max _{a_{i}} \Pi^{i}\left(a_{i}, a_{j}^{t}\left(\mathbf{Y}^{t-1}\right), \mathbf{Y}^{t-1}\right)+\delta V^{i, t}\left(\left(a_{i}, a_{j}^{t}\left(\mathbf{Y}^{t-1}\right)\right)+\mathbf{Y}^{t-1}\right)
$$

is differentiable in $\mathbf{Y}^{t-1}$, and

$$
\begin{aligned}
\frac{\partial}{\partial Y_{i}^{t-1}} V^{i, t-1}\left(\mathbf{Y}^{t-1}\right)= & \Pi_{Y_{i}}^{i}\left(\mathbf{a}^{t}\left(\mathbf{Y}^{t-1}\right), \mathbf{Y}^{t-1}\right)+\delta V_{Y_{i}}^{i, t}\left(\mathbf{a}^{t}\left(\mathbf{Y}^{t-1}\right)+\mathbf{Y}^{t-1}\right) \\
& +\left(\Pi_{a_{j}}^{i}\left(\mathbf{a}^{t}\left(\mathbf{Y}^{t-1}\right), \mathbf{Y}^{t-1}\right)+\delta V_{Y_{j}}^{i, t}\left(\mathbf{a}^{t}\left(\mathbf{Y}^{t-1}\right)+\mathbf{Y}^{t-1}\right)\right) \frac{\partial}{\partial Y_{i}^{t-1}} a_{j}^{t}\left(\mathbf{Y}^{t-1}\right) .
\end{aligned}
$$

The derivative $\frac{\partial}{\partial Y_{j}^{t-1}} V^{i, t-1}\left(\mathbf{Y}^{t-1}\right)$ is obtained analogously. Since the equilibrium policies are assumed to be continuously differentiable, the derivatives of the value function are continuous as well.

Thus, since $V^{i, T-1}\left(\mathbf{Y}^{T-1}\right)$ is continuously differentiable, by induction the value function in each period is continuously differentiable.

Step 3: Establish conditions required for weak increasing dominance in the final period, $T$.

Now, assume for simplicity that the value function and policy function in each period are twice differentiable (if this is not true, we can redo the following analysis with differences rather than derivatives). Consider the properties required for increasing dominance. As $\Pi^{i}$ satisfies (WID), (WID-D1), and (WID-D2) by assumption, analogous conditions hold replacing $\Pi^{i}$ with $\Pi^{i}+\delta V^{i, t}$, if:

$$
V_{Y_{i}, Y_{j}}^{i, t} \leq 0, V_{Y_{i}, Y_{i}}^{i, t} \geq 0, \text { and } V_{Y_{j}, Y_{j}}^{i, t} \geq 0
$$

Consider first whether $V^{i, T-1}$ satisfies (WID-V). Observe that $V^{i, T-1}\left(\mathbf{Y}^{T-1}\right)=\Pi^{i}\left(\mathbf{a}^{T}\left(\mathbf{Y}^{T-1}\right), \mathbf{Y}^{T-1}\right)$. Differentiating and using the envelope theorem as described above, for $i \neq j, \frac{\partial^{2}}{\partial Y_{i}^{T-1} \partial Y_{j}^{T-1}} \Pi^{i}\left(\mathbf{a}^{T}\left(\mathbf{Y}^{T-1}\right), \mathbf{Y}^{T-1}\right)$ can be written as follows: ${ }^{41}$

$$
\begin{aligned}
& \Pi_{Y_{i}, Y_{j}}^{i}+\Pi_{Y_{i}, a_{i}}^{i} \frac{\partial}{\partial Y_{j}^{T-1}} a_{i}^{T}\left(\mathbf{Y}^{T-1}\right)+\Pi_{Y_{i}, a_{j}}^{i} \frac{\partial}{\partial Y_{j}^{T-1}} a_{j}^{T}\left(\mathbf{Y}^{T-1}\right) \\
& +\Pi_{Y_{j}, a_{j}}^{i} \frac{\partial}{\partial Y_{i}^{T-1}} a_{j}^{T}\left(\mathbf{Y}^{T-1}\right)+\Pi_{a_{j}}^{i} \frac{\partial^{2}}{\partial Y_{i}^{T-1} \partial Y_{j}^{T-1}} a_{j}^{T}\left(\mathbf{Y}^{T-1}\right) \\
& +\Pi_{a_{i}, a_{j}}^{i} \frac{\partial}{\partial Y_{i}^{T-1}} a_{j}^{T}\left(\mathbf{Y}^{T-1}\right) \frac{\partial}{\partial Y_{j}^{T-1}} a_{i}^{T}\left(\mathbf{Y}^{T-1}\right)+\Pi_{a_{j}, a_{j}}^{i} \frac{\partial}{\partial Y_{i}^{T-1}} a_{j}^{T}\left(\mathbf{Y}^{T-1}\right) \frac{\partial}{\partial Y_{j}^{T-1}} a_{j}^{T}\left(\mathbf{Y}^{T-1}\right)
\end{aligned}
$$

\footnotetext{
${ }^{41}$ Here and in the following, we drop the arguments $\left(a^{T}\left(Y^{T}\right), Y^{T}\right)$ to simplify the exposition.
} 
Note that $\frac{\partial}{\partial Y_{j}^{T-1}} a_{j}^{T}\left(Y^{T-1}\right) \geq 0$ and $\frac{\partial}{\partial Y_{j}^{T-1}} a_{i}^{T}\left(Y^{T-1}\right) \leq 0$ by Lemma 3. Thus, the following are sufficient to guarantee that $\frac{\partial^{2}}{\partial Y_{i}^{T-1} \partial Y_{j}^{T-1}} \Pi^{i}\left(\mathbf{a}^{T}\left(\mathbf{Y}^{T-1}\right), \mathbf{Y}^{T-1}\right) \leq 0$ for $i \neq j$ : WID, WID-D1, WIDD2, and WID-A (observing that by exchangeability, the signs of the derivatives of $a_{j}^{T}$ can be inferred).

Similarly, $\frac{\partial^{2}}{\partial\left(Y_{i}^{T-1}\right)^{2}} \Pi^{i}\left(\mathbf{a}^{T}\left(\mathbf{Y}^{T-1}\right), \mathbf{Y}^{T-1}\right)$ is given by:

$$
\begin{array}{r}
\Pi_{Y_{i}, Y_{i}}^{i}+\Pi_{Y_{i}, a_{i}}^{i} \frac{\partial}{\partial Y_{i}^{T-1}} a_{i}^{T}\left(\mathbf{Y}^{T-1}\right)+2 \Pi_{Y_{i}, a_{j}}^{i} \frac{\partial}{\partial Y_{i}^{T-1}} a_{j}^{T}\left(\mathbf{Y}^{T-1}\right)+\Pi_{a_{j}}^{i} \frac{\partial^{2}}{\partial\left(Y_{i}^{T-1}\right)^{2}} a_{j}^{T}\left(\mathbf{Y}^{T-1}\right) \\
+\Pi_{a_{i}, a_{j}}^{i} \frac{\partial}{\partial Y_{i}^{T}} a_{j}^{T}\left(\mathbf{Y}^{T-1}\right) \frac{\partial}{\partial Y_{i}^{T}} a_{i}^{T}\left(\mathbf{Y}^{T-1}\right)+\Pi_{a_{j}, a_{j}}^{i}\left(\frac{\partial}{\partial Y_{i}^{T}} a_{j}^{T}\left(\mathbf{Y}^{T-1}\right)\right)^{2}
\end{array}
$$

This is positive under the same set assumptions; finally, these assumptions are also sufficient to guarantee that $\frac{\partial^{2}}{\partial\left(Y_{j}^{T-1}\right)^{2}} \Pi^{i}\left(\mathbf{a}^{T}\left(\mathbf{Y}^{T-1}\right), \mathbf{Y}^{T-1}\right)$ is positive, as can be verified in a similar way.

Step 4: Use induction to show that WID-V holds for each $t$.

The assumptions of the Proposition guarantee that WID-A holds for all $t$, and that WID-V holds for $t=T$. Suppose that WID-V holds for arbitrary $t$. Then, following similar arguments to above, and since Step 2 established that $V^{i, t}$ is continuously differentiable for each $t$, the derivatives of $\Pi^{i}\left(\mathbf{a}^{t}\left(\mathbf{Y}^{t-1}\right), \mathbf{Y}^{t-1}\right)+\delta V^{i, t}\left(\mathbf{a}^{t}\left(\mathbf{Y}^{t-1}\right)+\mathbf{Y}^{t-1}\right)$ can be analyzed following the approach of Step 3. Thus, if WID-V holds in period $t$, it will hold for $t-1$. By induction, WID-V holds for all $t$.

Step 5: The assumptions of the Proposition together with WID-V imply that in each period $t$, Theorem 5 applies to guarantee weak increasing dominance.

Proof of Proposition 13: To prove this result, we use the following lemma (see, for example, Athey (1999)):

Lemma 14 Let $f: X \times Y \rightarrow \mathbb{R}$, and let $G^{x}(\bullet ; z)$ and $G^{y}(\bullet ; w)$ be probability distributions. If $f(x, y)$ satisfies increasing differences in $(x, y)$, and $G^{x}(\bullet ; z)$ and $G^{y}(\bullet ; w)$ are nonincreasing in $z$ and $w$, respectively, then $\int f(x, y) d G^{x}(x ; z)$ satisfies increasing differences in $(y ; z)$, and $\int f(x, y) d G^{x}(x ; z) d G^{y}(y ; w)$ satisfies increasing differences in $(w ; z)$.

Under (WID-O), $\frac{\partial^{2} \widehat{\pi}^{i}}{\partial Y_{i}^{2}}>0$ and $\frac{\partial^{2} \widehat{\pi}^{i}}{\partial Y_{i} \partial Y_{j}}<0$. Under our assumptions, $E \pi^{i}\left(\mathbf{a}^{t}, \mathbf{Y}^{t-1}\right) \equiv \int \hat{\pi}^{i}\left(\mathbf{Y}^{t-1}+\right.$ $\left.\mathbf{y}^{t}\right) \prod_{j} d \hat{H}^{j}\left(y_{j}^{t} \mid a_{j}^{t}\right)$. Since the integral is a linear operator, (WID-O) immediately implies $\left(E \pi^{i}\right)_{Y_{i}, Y_{i}} \geq$ 0 and $\left(E \pi^{i}\right)_{Y_{i}, Y_{j}} \leq 0$. Since (WID-O) implies that $\hat{\pi}^{i}$ has increasing differences in $\left(y_{i}^{t} ; y_{j}^{t}\right)$, Lemma 14 implies that $\left(E \pi^{i}\right)_{a_{i}, a_{j}} \leq 0$. Further, since (WID-O) implies that $\hat{\pi}^{i}$ has increasing differences in $\left(y_{i}^{t} ; Y_{i}^{t}\right)$ and, for $j \neq i,\left(y_{i}^{t} ;-Y_{j}^{t}\right)$ and $\left(y_{j}^{t} ;-Y_{i}^{t}\right)$, Lemma 14 implies that $\left(E \pi^{i}\right)_{a_{i}, Y_{i}} \geq 0$, and, for $i \neq j,\left(E \pi^{i}\right)_{a_{i}, Y_{j}} \leq 0$ and $\left(E \pi^{i}\right)_{a_{i}, a_{j}} \leq 0$.

\section{References}

Aghion, P., Harris, C. and Vickers, J. "Competition and Growth with Step-by-Step Innovation: An example." European Economic Review, Vol. 41 (1997), pp. 771-782. 
Amir, Rabah. "Cournot Oligopoly and the Theory of Supermodular Games." Games and Economic Behavior, Vol. 15 (1994), pp. 132-148.

Areeda, P. and Turner, D.F. "Predatory Pricing and Related Practices under Section 2 of the Sherman Act." Harvard Law Review, Vol. 88 (1975), pp. 697-733.

Athey, S. "Characterizing Properties of Stochastic Objective Functions." MIT Working Paper No. 96-1R, Revised 1999.

Athey, S. and Schmutzler, A. "Product and Process Flexibility in an Innovative Environment," RAND Journal of Economics, Vol. 26 (1995), pp. 557-574.

Bagwell, K. and Ramey, G. "Coordination Economies, Advertising, and Search Behavior in Retail Markets." American Economic Review, Vol. 84 (1994), pp. 498-517.

Bagwell, K., Ramey, G., and Spulber, D.F. "Dynamic Retail Price and Investment Competition." RAND Journal of Economics, Vol. 28 (1997), 207-227.

Bagwell, K., and R.W. Staiger. "The Sensitivity of Strategic and Corrective R\&D Policy in Oligopolistic Industries." Journal of International Economics, Vol. 36 (1994), pp. 133-150.

Baumol, W. "Quasi-Permanence of Price Reductions: A Policy for Prevention of Predatory Pricing." Yale Law Journal, Vol. 89 (1979), pp. 1-26.

Beath, J., Katsoulacos, Y., Ulph, D. "Sequential Product Innovation and Industry Evolution." The Economic Journal, Vol. 97 (1987), pp. 32-43.

Brander, J. and Spencer, B. "Export Subsidies and International Market Share Rivalry." Journal of International Economics, Vol. 18 (1-2). pp. 83-100. February 1985.

Budd, C., Harris, C., Vickers, J. "A Model of the Evolution of Duopoly: Does the Asymmetry between Firms Tend to Increase or Decrease?" Review of Economic Studies, Vol. 60 (1993), pp. 543-573.

Bulow, J., Geanakoplos, J., and Klemperer, P. "Multimarket Oligopoly: Strategic Substitutes and Complements." Journal of Political Economy, Vol. 93 (1985). pp. 488-511.

Cabral, L.M.B. "Increasing Dominance with No Efficiency Effect." Mimeo, London Business School, 1999.

Cabral, L.M.B., Riordan M.H. "The Learning Curve, Market Dominance, and Predatory Pricing." Econometrica, Vol. 62 (1994), pp. 1115-1140.

d'Aspremont, C., Gabszewicz, J., Thisse, J.-F. "On Hotelling's Stability in Competition." Econometrica, Vol. 17 (1979), pp. 1145-1151

Davis, P. "Empirical Methods for Discrete Games: Quantity Competition in the Presence of Indivisibilities and Heterogeneous Firms." MIT Sloan School of Business, 1999.

Dixit, A. "A Model of Duopoly suggesting a Theory of Entry Barriers." Bell Journal of Economics, Vol. 10 (1979), pp. 20-32 
Dixit, A. "Comparative Statics for Oligopoly," International Economic Review. Vol. 27 (1986), pp. 107-122.

Ellickson, P. "Vertical Product Differentiation and Competition in the Supermarket Industry." Ph.D. Thesis, MIT, 1999.

Eswaran, M. and Gallini, N. "Patent Policy and the Direction of Technological Change." RAND Journals of Economics, Vol. 27 (1996), pp. 72-74.

Farrell, J. and Saloner, G. "Installed Base and Compatibility: Innovation, Product Preannouncements, and Predation." American Economic Review, 76 (1986), pp. 940955.

Fershtman, C. and Judd, K. L. "Equilibrium Incentives in Oligopoly." American Economic Review, Vol. 77 (1987), pp. 927-940.

Flaherty, T. M. "Industry Structure and Cost-Reducing Investment." Econometrica, Vol. 48 (1980), pp. 1187-1209.

Fudenberg, D. and J. Tirole. "The Fat-Cat Effect, the Puppy-Dog Ploy, and the Lean and Hungry Look.". American Economic Review, Vol. 74 (1984), pp. 361-66.

Fudenberg, D. and J. Tirole. Game Theory, Cambridge, Mass. and London: MIT Press, 1991.

Gruber, H. Learning and Strategic Product Innovation: Theory and Evidence for the Semiconductor Industry. Amsterdam: North-Holland, 1994.

Katz, M. and Shapiro, C. "Technology Adoption in the Presence of Network Externalities." Journal of Political Economy, Vol. 94 (1986), pp. 822-841.

Klepper, S. "Entry, Exit, Growth, and Innovation over the Product Life Cycle," The American Economic Review, Vol. 86 (1996), pp. 562-583.

Lee, T. and Wilde, L.L. "Market Structure and Innovation: A Reformulation." Quarterly Journal of Economics, Vol. 94 (1980) pp. 429-436.

Loury, G. "Market Structure and Innovation." Quarterly Journal of Economics, Vol. 93 (1979), pp. 395-410.

Milgrom, P. and J. Roberts. "Rationalizability, Learning, and Equilibrium in Games with Strategic Complementarities." Econometrica, Vol. 58 (1990), pp. 1255-1277.

Moulin, H. Axioms of Cooperative Decision Making. Cambridge University Press: New York, 1988.

Novshek, W. "On the Existence of Cournot Equilibrium." Review of Economic Studies, Vol. 52 (1985), pp. 85-98.

Reinganum, J.F. "Innovation and Industry Evolution." Quarterly Journal of Economics, Vol. 99 (1985), pp. 81-99.

Rogerson, W.P.,. "The Social Costs of Monopoly and Regulation: A Game-Theoretic Analysis." Bell Journal of Economics, Vol. 13 (1982), pp. 391-401. 
Ronnen, U. "Minimum Quality Standards, Fixed Costs, and Competition." RAND Journal of Economics, Vol. 22 (1991), pp. 490-504.

Selten, R., Preispolitik der Mehrproduktunternehmung in der Statischen Theorie, SpringerVerlag, Berlin, 1970.

Shaked, A. and Sutton, J. "Relaxing Price Competition through Product Differentiation." Review of Economic Studies, Vol. 49 (1982), pp. 3-19.

Spencer, B. and Brander, J. "International R \& D Rivalry and Industrial Strategy." Review of Economic Studies, Vol. 50 (1983), pp. 707-22.

Sutton, J. Sunk Costs and Market Structure. MIT Press: Cambridge, 1991.

Sutton, J. Technology and Market Structure. MIT Press: Cambridge, 1998.

Tirole, J. The Theory of Industrial Organization. MIT Press: Cambridge, 1988.

Topkis, D. "Minimizing a Submodular Function on a Lattice." Operations Research, Vol. 26 (1978), pp. 305-321.

Topkis, D. "Equilibrium Points in Nonzero-Sum n-person Submodular Games," Operations Research, Vol. 27 (1979), pp. 305-321.

Vickers, J. "The Evolution of Market Structure when there is a Sequence of Innovations." The Journal of Industrial Economics, Vol. 35 (1986), pp. 1-13.

Vives, X. "Nash Equilibrium with Strategic Complementarities," Journal of Mathematical Economics, Vol. 19 (1990), pp. 305-321. 